\title{
Variation in effect of intervention studies in research on sickness absence
}

This article was published in the following Dove Press journal:

Open Access Journal of Clinical Trials

12 April 2012

Number of times this article has been viewed

\section{Hans Joergen Soegaard \\ Research Unit West, Centre for Psychiatric Research, Aarhus University Hospital, Risskov}

Correspondence: Hans Joergen Soegaard Forskningsenhed Vest, Center for Psykiatrisk Forskning, GI Landevej 43, 7400 Herning, Denmark

Tel +4578474660

Fax +4578474637

Email hans-joergen.soegaard@ps.rm.dk
Background: Intervention studies in sickness absence research demonstrate a low effect and ambiguous results in reducing sickness absence and improving work status. The aim of this study was to determine if the effect of interventions is related to type of intervention, target population, inclusion criteria used, and impact of the scientific quality of the studies.

Methods: Based on a structured review of 57 studies, short-term, medium-term, and longterm effects were analyzed with regard to the type of intervention, target population, inclusion criteria, and scientific quality of the studies.

Results: The overall result was that the effect rate was low, ie, about $20 \%$ for short-term effect (up to 6 months) and medium-term effect (6-12 months), and 40\% for long-term effect ( $\geq 12$ months). Interventions using stress reduction were most effective with regard to shortterm and medium-term effects, whereas collaborative care was most effective for long-term effects. The effects were related to the inclusion criteria and, to a minor degree, to the scientific quality of the studies.

Conclusion: In the field of sickness absence research, more attention should be paid to the interrelationship between the types of interventions, target populations, and inclusion criteria for the studies. Larger studies of high methodological quality are needed. Steps should be taken to standardize outcome measures.

Keywords: nonparticipation, sickness absence, return to work, controlled trial, review

\section{Background}

Mental disorders impose suffering and reduce quality of life for the individuals living with these conditions. These disorders also impose an economic burden on society, primarily due to indirect costs in the form of sickness absence, early retirement, and early death. ${ }^{1,2}$ In addition, mental disorders significantly influence the outcome of comorbid medical illnesses, ${ }^{3}$ family dysfunction, and induce a risk of mental and physical illness among family members. ${ }^{4}$ With regard to sickness absence, the burden is, in particular, due to common mental disorders, such as depression, anxiety, and somatoform disorders. These disorders primarily cause the burden because they occur rather frequently. ${ }^{1,5}$

The Organization for Economic Cooperation and Development reports that mental health problems now account for one third of all new disability claims on average, and up to $40 \%-50 \%$ in some countries. ${ }^{6}$ The frequency of mental disorders among incident individuals on long-term sickness absence (more than eight continuous weeks of sickness absence) is about $50 \%{ }^{7}$ The burden imposed by common mental disorders is increasing as documented in a Norwegian study, where evidence was found that 
the cumulative incidence of long-term sickness absence for women with mental disorders increased from 1.7\% in 1994 to $4.6 \%$ in 2000 , and for men from $0.8 \%$ to $2.2 \%{ }^{8}$

This burden has motivated clinicians, rehabilitation officers, and researchers to develop interventions aimed at improving mental health and quality of life. The majority of studies in this area have used outcome measures for mental health and quality of life. In addition, an aim has been to reduce sickness absence and improve the fraction of positive work status. However, the studies applying outcome measures with regard to sickness absence and work status measures are much fewer. ${ }^{9-16}$

The intervention studies have been the subject of several reviews. The reviews which have applied sickness absence and work status outcome measures indicate a large ambiguity with regard to effect on these outcome measures. This ambiguity may be caused by a variety of factors, such as the type of intervention, target population, inclusion criteria, and methodological issues. These methodological issues have been addressed by Moncrieff et al, ${ }^{17}$ who stated that within the field of psychiatry several important issues are not well covered by the majority of published checklists and rating systems for assessment of the quality of studies. This is due to the fact that, in psychiatry, interventions take many forms. Subsequently, detailed reports of the interventions are necessary. In addition, some interventions, such as psychotherapy, make it impossible to blind the intervention in regards to the patients. Psychiatric diagnoses are complex. In several studies, the diagnoses are compiled into a group of neuroses (common mental disorders). The nature of the interventions makes randomization impossible. Consequently, Moncrieff et al $^{17}$ developed an instrument consisting of 23 items, which is applicable to studies of nonpsychotic disorders. Evidence retrieved from studies of low quality should be assessed with caution, as documented by Moher et al, ${ }^{18}$ who showed that the overall quality of a study predicts the obtained effect size. The issues mentioned by Moncrieff et $a{ }^{17}$ concern studies in psychiatry, but they can certainly be applied within the field of mental disorders and psychological distress in sickness absence as well.

The aim of the study was to assess the results of intervention studies with attention to the outcome measures of sickness absence and work status. By means of a systematic literature review, it was investigated whether or not the effect rates of the examined studies were dependent on the following factors: type of intervention; scientific quality of the study; target population and the population of eligible individuals; inclusion criteria; and fraction of nonparticipation in the target group, the group of eligible participants, and at follow-up.

\section{Methods}

\section{Literature review}

The literature search aimed to identify intervention studies which met the following criteria:

- Studies must include outcome measures for sickness absence or work status

- Interventions must possess the following characteristics:

- Be primary, secondary, or tertiary interventions

- Be aimed at reducing psychological distress and improving quality of life by one or more of the following types of interventions: organizational interventions, stress reducing interventions, feedback interventions, physical interventions, therapeutic interventions, and collaborative care. The studies were included if they involved screening for the purpose of detecting common mental disorders.

- Participants must be healthy individuals with mental distress or diagnosed as having a common mental disorder such as depression, anxiety, or a somatoform disorder (primary intervention). However, this delimitation created ambiguity with regard to which studies to include. Studies including medically unexplained symptoms were included, whereas studies focusing on somatic conditions and those that exclusively addressed alcohol abuse or drug abuse were excluded. The ambiguity concerning the delimitation of studies was due to the fact that many studies concerning individuals with musculoskeletal symptoms, low back pain, heart diseases, and other somatic conditions examined the effect on psychological distress and quality of life.

- Be controlled studies, including a quasi-experimental design, pre/post design, randomized controlled trials, cluster-randomized trials, and wait-list control studies.

The literature search was carried out in the PubMed (Medline), Embase, PsycINFO, and Cochrane databases using the criteria shown in Figure 1. The search was supplemented with browsing. In total, the 57 studies presented in Table 1 were identified.

\section{Concepts Effect of a study}

The outcome measures for sickness absence and work status were several, often more than one in the same study. The outcome measures were: duration of sickness absence, counted in number of days, hours, or weeks within a given period; 
The PubMed search was carried out with the following MeSH words:

- Mental disorders or depression or anxiety or somatoform disorders or stress/psychological or professional burnout or mass screening

- Sick leave or absenteeism or efficiency/organizational

- Limitations: Clinical trial or controlled study or meta-analysis or review

The searches were combined by "and".

In PsycINFO, the search terms were:

- Mental disorder or adjustment disorders or affective disorders or endogenous depression or acute stress disorder or generalized anxiety disorder or obsessive compulsive disorder or panic disorder or phobias or social phobia or post-traumatic stress disorder or somatization disorder or occupational stress

- Employee leave or employee absenteeism

- Limitations: Controlled study or controlled study or cluster randomized study or meta-analysis or review

The searches were combined by "and".

In Embase, the criteria were the following keywords (exploded):

- Mental disease or depression or anxiety or somatoform disorder or job stress or burnout or mass screening

- Medical leave or absenteeism or work capacity or rehabilitation or work resumption or work disability

- Limitations: Controlled study or controlled study or cluster randomized study or meta-analysis or review

The searches were combined by "and".

The Cochrane database was searched for the following reviews:

- Mental disorder or psychiatric disorder or depression or anxiety or somatoform disorder or stress or burnout or mass screening

- Sickness absence or sick leave or absenteeism or return to work

The search was supplemented with browsing of the studies identified by the search mentioned above.

Figure I Search criteria.

rates of individuals who returned to work within a given period; and fractions of individuals having retained work within a given period. The effect was considered positive if at least one parameter indicated effect. The effect rate was defined as the fraction of interventions showing effect among the number of interventions where the effect was examined. This was done separately for short-term effect (up to 6 months after the initiation of the intervention), medium-term effect (from 6 months up to one year), and long-term effect (one year and longer).

\section{Intervention group and control group}

Some studies involved more interventions which were compared with the same control group. The control groups depended on the target population; in some studies, no intervention, and, in others, care as usual. Care as usual differs very much depending on the target group. It was not possible to define a control group in five studies. The studies carried out by van Rhenen et al, ${ }^{19,20} \mathrm{Knekt}$ et al, ${ }^{21} \mathrm{Krogh}$ et al, ${ }^{22} \mathrm{Schene}$ et al, ${ }^{23}$ and Stenlund et $\mathrm{al}^{24}$ were included in the review. However, when it came to analyses that compared intervention groups with control groups, these studies were excluded. Furthermore, the studies by Bakker et $\mathrm{al}^{25,26}$ and
Soegaard and $\mathrm{Bech}^{27}$ showed an effect in subgroups but not in the total group of analyzed participants. These studies were registered as being without effect.

\section{Types of interventions}

The interventions were categorized as being organizational, or focused on stress reduction, feedback, physical, therapy, education, or collaborative care.

Organizational interventions were directed towards the organizational structure in workplaces with the aim of reducing stress, but not directed towards each individual employee. However, these interventions involved the employees in identifying the stress-creating factors in the workplaces and in the development of actions to reduce these stress-creating factors. ${ }^{15,28-37}$

Stress reduction interventions were directed towards the individuals participating in a particular study employing this type of intervention. The individuals were informed about stress-creating factors and means to reduce stress in the form of posted information, information given at seminars or meetings, or at an individual level. ${ }^{27,30,32,33,38-55}$ The stressreducing intervention in the study by Saksvik and Nytro ${ }^{49}$ 
Table I Overview of the 57 reviewed studies

\begin{tabular}{|c|c|c|c|c|c|}
\hline \multirow[t]{2}{*}{ Study } & \multicolumn{5}{|l|}{ Inclusion criteria } \\
\hline & Target population & Diagnosis & Stress score & $\begin{array}{l}\text { Sickness absence/return } \\
\text { to work }\end{array}$ & Quality score \\
\hline Bakker et a ${ }^{25}$ & Primary care & No & Yes & Plus & 37 \\
\hline \multicolumn{6}{|l|}{ Uegaki et $\mathrm{a}^{26}$} \\
\hline Blonk et $\mathrm{al}^{38}$ & Company & CMD/stress & No & Plus & 21 \\
\hline Bond and Bunce ${ }^{28}$ & Company & No & No & No & 16 \\
\hline Bonde et $\mathrm{a}^{56}$ & $\mathrm{OH} /$ stress clinic & No & No & Risk & 31 \\
\hline Boumans and Landeweerd ${ }^{29}$ & Company & No & No & No & 14 \\
\hline Brattberg $g^{39,40}$ & Population & CMD/stress & No & Plus & 19 \\
\hline Brouwers et $\mathrm{al}^{57,58}$ & Population & No & Yes & Plus & 34 \\
\hline de Boer et $\mathrm{al}^{41}$ & $\mathrm{OH} /$ stress clinic & No & No & Risk & 29 \\
\hline de Vente et $\mathrm{al}^{42}$ & $\mathrm{OH} /$ stress clinic & CMD/stress & No & Plus & 31 \\
\hline Dierendonck et $\mathrm{al}^{72}$ & Company & No & No & No & 18 \\
\hline Duijts et a ${ }^{59}$ & Company & No & Yes & No & 34 \\
\hline Eriksen et al ${ }^{43}$ & Company & No & No & No & 33 \\
\hline Fleten and Johnsen ${ }^{44}$ & Population & CMD/stress & No & Plus & 32 \\
\hline Ginsberg et $\mathrm{al}^{73}$ & Primary care & CMD/stress & No & No & 21 \\
\hline Grossi and Santell ${ }^{45}$ & $\mathrm{OH} /$ stress clinic & CMD/stress & No & Plus & 26 \\
\hline Hollinghurst et $\mathrm{a}^{74}$ & Primary care & Depression & No & No & 30 \\
\hline \multicolumn{6}{|l|}{ Kessler et $\mathrm{al}^{78}$} \\
\hline Huibers et $\mathrm{al}^{75}$ & $\mathrm{OH} /$ stress clinic & CMD/stress & Yes & Plus & 36 \\
\hline Kant et $\mathrm{al}^{60}$ & $\mathrm{OH} /$ stress clinic & No & Yes & Risk & 35 \\
\hline Karlson et $\mathrm{al}^{30}$ & Population & CMD/stress & No & Plus & 28 \\
\hline Kawakami et $\mathrm{a}^{31}$ & Company & No & Yes & No & 22 \\
\hline Kawakami et $a^{61}$ & Company & No & Yes & No & 19 \\
\hline Kendrick et al $\mathrm{a}^{76,77}$ & Primary care & CMD/stress & Yes & No & 33 \\
\hline Knekt et $\mathrm{a}^{21}$ & Psychiatric patients & CMD/stress & No & No & 30 \\
\hline Kobayashi et a $\mathrm{a}^{32}$ & Company & No & No & No & 28 \\
\hline
\end{tabular}




\begin{tabular}{|c|c|c|c|c|c|c|}
\hline \multicolumn{2}{|l|}{ Nonparticipation } & \multirow{2}{*}{$\begin{array}{l}\text { Intervention } \\
\text { Number in intervention } \\
\text { and control group }\end{array}$} & \multirow{2}{*}{$\frac{\text { Follow-up }}{\text { Nonparticipation \% }}$} & \multicolumn{3}{|l|}{ Effect } \\
\hline Target group $\%$ & Eligible group \% & & & $\begin{array}{l}\text { Short-term } \\
<6 \text { months }\end{array}$ & $\begin{array}{l}\text { Medium-term } \\
6-12 \text { months }\end{array}$ & $\begin{array}{l}\text { Long-term } \\
\text { 12+ months }\end{array}$ \\
\hline \multirow[t]{2}{*}{-} & 33.1 & E: 227 & E: 13.2 & - & - & - \\
\hline & & CAU: 206 & CAU: 16.5 & & & \\
\hline \multirow[t]{3}{*}{-} & 64.7 & $\mathrm{~T}: 40$ & $\mathrm{~T}: 25.0$ & + & - & \\
\hline & & $\mathrm{S}+\mathrm{F}+\mathrm{T}: 40$ & $\mathrm{~S}+\mathrm{F}+\mathrm{T}: 25.0$ & & & \\
\hline & & CAU: 42 & CAU: 33.3 & & & \\
\hline \multirow[t]{2}{*}{-} & 19.8 & O: 48 & O: 43.8 & & & + \\
\hline & & CAU: 49 & CAU: 46.9 & & & \\
\hline \multirow[t]{2}{*}{0.0} & 24.3 & F: 48 & F: 9.8 & - & - & - \\
\hline & & CAU: 49 & CAU: 13.0 & & & \\
\hline \multirow[t]{2}{*}{-} & 59.3 & O: 23 & O: - & & - & - \\
\hline & & CAU: 36 & CAU: - & & & \\
\hline \multirow[t]{2}{*}{-} & 0.0 & S: 20 & S: 16.7 & + & & - \\
\hline & & CAU: 20 & CAU: 16.7 & & & \\
\hline \multirow[t]{2}{*}{-} & 8.8 & $F+T+E: 98$ & $F+T+E: 3 . I$ & - & - & - \\
\hline & & CAU: 96 & CAU: 6.3 & & & \\
\hline \multirow[t]{2}{*}{27.5} & 27.5 & $S+F+C: 6 I$ & $S+F+C: 34.4$ & & - & + \\
\hline & & CAU: 55 & CAU: 38.2 & & & \\
\hline \multirow[t]{3}{*}{-} & - & $S+T-i: 28$ & $S+T-i: 21.4$ & - & - & \\
\hline & & S + T-g: 28 & $S+T-g: 32.1$ & - & - & \\
\hline & & CAU: 26 & CAU: 50.0 & & & \\
\hline \multirow[t]{2}{*}{58.0} & - & $\mathrm{T}: 36$ & & & + & + \\
\hline & & CAU: 113 & & & & \\
\hline \multirow[t]{2}{*}{58.0} & 31.7 & F: 76 & F: 25.0 & & + & + \\
\hline & & CAU: 75 & CAU: 18.7 & & & \\
\hline \multirow[t]{4}{*}{32.0} & 7.9 & P: 189 & P: 39.7 & - & & - \\
\hline & & $\mathrm{T}: 162$ & $\mathrm{~T}: 39.5$ & - & & - \\
\hline & & $S+F+P: 165$ & $S+F+P: 43.0$ & - & & - \\
\hline & & CAU: 344 & CAU: 51.7 & & & \\
\hline \multirow[t]{2}{*}{0.0} & 0.0 & S + F: 595 & $S+F: 9.6$ & + & + & + \\
\hline & & CAU: 595 & CAU: 24.0 & & & \\
\hline \multirow[t]{2}{*}{13.4} & 20.7 & $\mathrm{~T}: 46$ & $\mathrm{~T}: 54.2$ & & & - \\
\hline & & CAU: 46 & CAU: 39.1 & & & \\
\hline- & 14.0 & $S+F+P: 12$ & - & - & - & - \\
\hline & & CAU: 12 & & & & \\
\hline 18.6 & 0.0 & $\mathrm{~T}: 149$ & T: 50.3 & & + & \\
\hline & & CAU: 148 & CAU: 55.4 & & & \\
\hline 51.4 & 92.2 & $T+E: 76$ & $\mathrm{~T}+\mathrm{E}: 7.9$ & - & - & - \\
\hline & & CAU: 75 & CAU: 9.3 & & & \\
\hline 49.8 & 0.0 & F: 132 & F: 25.0 & & & - \\
\hline & & CAU: $|3|$ & CAU: 0.0 & & & \\
\hline 29.2 & 25.5 & $O+S+F+C: 108$ & $\mathrm{O}+\mathrm{S}+\mathrm{F}+\mathrm{C}: 31.5$ & - & + & + \\
\hline & & CAU: 122 & CAU: 39.3 & & & \\
\hline- & - & O: 111 & O: 28.8 & & & - \\
\hline & & CAU: 186 & CAU: 41.9 & & & \\
\hline- & 6.8 & F: 9I & F: 11.0 & & & - \\
\hline & & CAU: 88 & CAU: 12.5 & & & \\
\hline 9.1 & 11.8 & $\mathrm{~T}: 90$ & $\mathrm{~T}: 10.0$ & & - & \\
\hline & & E: 79 & E: 6.3 & & - & \\
\hline & & CAU: 78 & CAU: 5.1 & & & \\
\hline- & 29.0 & T-stt: |0| & T-stt: 31.7 & & & NC \\
\hline & & T-Itt: 128 & T-Itt: 28.1 & & & \\
\hline & & T-sft: 97 & T-sft: 38.1 & & & \\
\hline- & O: । I.5 CAU: 11.8 & $\mathrm{O}+\mathrm{S}: 348$ & $\mathrm{O}+\mathrm{S}: 7.8$ & & & - \\
\hline & & CAU: 918 & CAU: 18.3 & & & \\
\hline
\end{tabular}


Table I (Continued)

\begin{tabular}{|c|c|c|c|c|c|}
\hline \multirow[t]{2}{*}{ Study } & \multicolumn{5}{|l|}{ Inclusion criteria } \\
\hline & Target population & Diagnosis & Stress score & $\begin{array}{l}\text { Sickness absence/return } \\
\text { to work }\end{array}$ & Quality score \\
\hline Krogh et $\mathrm{al}^{22}$ & $\mathrm{OH} /$ stress clinic & Depression & Yes & No & 38 \\
\hline Lexis et al ${ }^{79}$ & Company & No & Yes & Risk & 38 \\
\hline Maes et $\mathrm{a}^{33}$ & Company & No & No & No & 20 \\
\hline Munz et $\mathrm{al}^{34}$ & Company & No & No & No & 7 \\
\hline Netterstrom and Bech ${ }^{47}$ & $\mathrm{OH} /$ stress clinic & CMD/stress & No & No & 23 \\
\hline Nystuen and Hagen ${ }^{80}$ & Population & CMD/stress & No & Plus & 36 \\
\hline Proper et $\mathrm{a}^{62,63}$ & Company & No & No & No & 27 \\
\hline Rebergen et al ${ }^{64,65}$ & Company & CMD/stress & No & Plus & 36 \\
\hline Reynolds 35 & Company & No & No & No & 10 \\
\hline Rollman et $\mathrm{al}^{48}$ & Primary care & Anxiety & Yes & No & 37 \\
\hline Rost et $\mathrm{al}^{86}$ & Primary care & Depression & Yes & No & 33 \\
\hline \multicolumn{6}{|l|}{ Lo Sasso et al ${ }^{85}$} \\
\hline Rutz et al ${ }^{87,88}$ & Primary care & No & No & No & 19 \\
\hline Saksvik and Nytro ${ }^{49}$ & Company & No & No & No & 13 \\
\hline Schene et $\mathrm{a}^{23}$ & Psychiatric patients & Depression & Yes & Plus & 31 \\
\hline Schilte et $\mathrm{a}^{81}$ & Primary care & Somatization & Yes & No & 35 \\
\hline Schoenbaum et a $\left.\right|^{82,83}$ & Primary care & Depression & Yes & No & 33 \\
\hline Schrijnemaekers et $\mathrm{al}^{36}$ & Company & No & No & No & 29 \\
\hline Simon et $\mathrm{a}^{93}$ & Primary care & Depression & Yes & No & 29 \\
\hline \multicolumn{6}{|l|}{ Katon et $\mathrm{al}^{91,92}$} \\
\hline Smith et $\mathrm{al}^{50}$ & Primary care & Somatization & No & No & 37 \\
\hline \multicolumn{6}{|l|}{ Luo et $\mathrm{al}^{46}$} \\
\hline Soegaard and Bech ${ }^{27}$ & Population & No & Yes & Plus & 33 \\
\hline Stenlund et $\mathrm{al}^{24}$ & $\mathrm{OH} /$ stress clinic & CMD/stress & Yes & Plus & 35 \\
\hline Svensson et al ${ }^{51,52}$ & Company & No & No & No & 34 \\
\hline Taimela et $\mathrm{a}^{66,67}$ & Company & Depression & Yes & Risk & 37 \\
\hline
\end{tabular}

Taimela et al ${ }^{6,67}$

Company

Depression Yes 


\begin{tabular}{|c|c|c|c|c|c|c|}
\hline \multicolumn{2}{|c|}{ Nonparticipation } & \multirow{2}{*}{$\begin{array}{l}\text { Intervention } \\
\text { Number in intervention } \\
\text { and control group }\end{array}$} & \multirow{2}{*}{$\begin{array}{l}\text { Follow-up } \\
\text { Nonparticipation \% }\end{array}$} & \multicolumn{3}{|l|}{ Effect } \\
\hline Target group \% & Eligible group $\%$ & & & $\begin{array}{l}\text { Short-term } \\
<6 \text { months }\end{array}$ & $\begin{array}{l}\text { Medium-term } \\
\text { 6-12 months }\end{array}$ & $\begin{array}{l}\text { Long-term } \\
12+\text { months }\end{array}$ \\
\hline \multirow[t]{3}{*}{24.9} & 7.8 & P-st: 55 & P-st: 16.4 & NC & & $\mathrm{NC}$ \\
\hline & & P-at: 55 & P-at: 16.4 & & & \\
\hline & & P-rt: 55 & P-rt: 32.7 & & & \\
\hline \multirow[t]{2}{*}{61.8} & 28.9 & $\mathrm{~T}: 69$ & $\mathrm{~T}: 37.7$ & & & - \\
\hline & & CAU: 70 & CAU: 32.9 & & & \\
\hline \multirow[t]{2}{*}{-} & 37.3 & $\mathrm{O}+\mathrm{S}+\mathrm{P}: 175$ & $O+S+P: 23.4$ & & & + \\
\hline & & CAU: 171 & CAU: 24.0 & & & \\
\hline \multirow[t]{2}{*}{-} & & $\mathrm{O}+\mathrm{F}: 26.7$ & $\mathrm{O}+\mathrm{F}: 55$ & - & & \\
\hline & & CAU: 68.0 & CAU: 24 & & & \\
\hline \multirow[t]{2}{*}{-} & 3.1 & $S+F+P+C: 63$ & $S+F+P+C: 0.0$ & + & & + \\
\hline & & CAU: 34 & CAU: 17.7 & & & \\
\hline \multirow[t]{2}{*}{0.0} & 85.3 & $\mathrm{~T}: 53$ & $\mathrm{~T}: 9.6$ & & - & - \\
\hline & & CAU: 50 & CAU: 24.0 & & & \\
\hline \multirow[t]{2}{*}{50.1} & - & $F+P:|3|$ & $F+P: 26.0$ & & - & \\
\hline & & CAU: 168 & CAU: 0.6 & & & \\
\hline \multirow[t]{2}{*}{-} & 50.9 & $\mathrm{~F}+\mathrm{T}+\mathrm{E}: 125$ & $F+T+E: 10.4$ & & & - \\
\hline & & CAU: 115 & CAU: 12.2 & & & \\
\hline \multirow[t]{2}{*}{-} & - & O: 37 F: 76 & - & & & - \\
\hline & & CAU: 43 & & & & \\
\hline \multirow[t]{2}{*}{17.2} & 46.5 & $S+F+E+C: 116$ & $S+F+E+C: 13.8$ & & & + \\
\hline & & CAU: 75 & CAU: 6.7 & & & \\
\hline \multirow[t]{8}{*}{-} & 34.8 & Consistently employed: & Consistently & - & - & - \\
\hline & & E: 96 & employed: & & & \\
\hline & & CAU: 102 & E: 39.6 & & & \\
\hline & & & CAU: 23.5 & & & \\
\hline & & Inconsistently & Inconsistently & - & + & - \\
\hline & & employed: & employed: & & & \\
\hline & & E: 62 & E: 21.0 & & & \\
\hline & & CAU: 66 & CAU: 19.7 & & & \\
\hline- & - & $\mathrm{E}$ & - & & & + \\
\hline \multirow[t]{2}{*}{57.8} & 26.0 & S: 30 & - & & & - \\
\hline & & CAU: 135 & & & & \\
\hline- & 16.9 & $\mathrm{~F}+\mathrm{T}: 30$ & F: 20.0 & & & NC \\
\hline & & $\mathrm{T}: 32$ & CAU: 25.0 & & & \\
\hline 32.9 & 43.1 & $\mathrm{~T}: 8 \mathrm{I}$ & $\mathrm{T}: 13.6$ & - & - & - \\
\hline & & CAU: 80 & CAU: 16.3 & & & \\
\hline 15.0 & 37.7 & E: 424 & $\mathrm{E}: 12.5$ & - & - & + \\
\hline & & T: 489 & $\mathrm{~T}: 18.0$ & - & - & + \\
\hline & & CAU: 443 & CAU: 12.9 & & & \\
\hline 2.6 & 0.7 & O: 154 & $0: 18.2$ & - & - & - \\
\hline & & CAU: 139 & CAU: 16.5 & & & \\
\hline 23.2 & 29.4 & C: 77 & C: 22.1 & - & - & \\
\hline & & CAU: 76 & CAU: 30.3 & & & \\
\hline 0.0 & 43.7 & $S+F+E+C: 101$ & $S+F+E+C: 3.0$ & & & - \\
\hline & & CAU: 105 & CAU: 2.9 & & & \\
\hline 53.6 & - & $S+F+C: 420$ & $S+F+C: 0.0$ & & & - \\
\hline & & CAU: 416 & CAU: 0.0 & & & \\
\hline- & 13.9 & $S+T: 67$ & $\mathrm{~T}: 19.4$ & & NC & NC \\
\hline & & $\mathrm{T}: 69$ & CAU: 43.4 & & & \\
\hline- & 12.8 & $S+P: 389$ & S + P: 54.5 & & & + \\
\hline & & CAU: 279 & CAU: 53.8 & & & \\
\hline 51.6 & 7.7 & High risk: & High risk: & & & + \\
\hline & & $F+C: 209$ & $F+C: 8.1$ & & & \\
\hline & & CAU: 209 & CAU: 8.1 & & & \\
\hline & & Medium risk: & Medium risk: & & & \\
\hline & & S: 268 & S: 6.3 & & & - \\
\hline & & CAU: 269 & CAU: 5.6 & & & \\
\hline
\end{tabular}

(Continued) 
Table I (Continued)

\begin{tabular}{|c|c|c|c|c|c|}
\hline \multirow[t]{2}{*}{ Study } & \multicolumn{5}{|l|}{ Inclusion criteria } \\
\hline & Target population & Diagnosis & Stress score & $\begin{array}{l}\text { Sickness absence/return } \\
\text { to work }\end{array}$ & Quality score \\
\hline Tveito and Eriksen ${ }^{53}$ & Company & No & No & No & 20 \\
\hline van der Feltz-Cornelis et $\mathrm{al}^{89}$ & $\mathrm{OH} /$ stress clinic & CMD/stress & Yes & Plus & 31 \\
\hline van der Klink et $\mathrm{al}^{54}$ & Company & CMD/stress & No & Plus & 30 \\
\hline van Oostrom et al $\left.\right|^{15,37}$ & $\mathrm{OH} /$ stress clinic & No & Yes & Plus & 35 \\
\hline van Rhenen et al ${ }^{19,20}$ & $\mathrm{OH} /$ stress clinic & No & Yes & No & 29 \\
\hline von Vultée et $a^{68,69}$ & Company & No & No & No & 22 \\
\hline Wang et $\mathrm{al}^{55}$ & $\mathrm{OH} /$ stress clinic & Depression & Yes & No & 33 \\
\hline Wells et $\mathrm{al}^{84}$ & Primary care & Depression & Yes & No & 33 \\
\hline Willert et $\mathrm{al}^{70,71}$ & $\mathrm{OH} /$ stress clinic & CMD/stress & Yes & No & 35 \\
\hline Yelin et $\mathrm{al}^{90}$ & Primary care & Anxiety & Yes & Risk & 22 \\
\hline
\end{tabular}

was somewhat different from that in other studies using stress-reducing intervention because it allowed employees in the Norwegian health care sector of a municipality to take up to five days of self-approved sick leave with full financial compensation up to four times a year.

Feedback interventions involved screening of individuals with regard to signs of distress or mental disorder, and, subsequently, individuals showing signs of distress were given individual feedback with regard to how to change their lifestyle and react to stressors in their individual lives and in

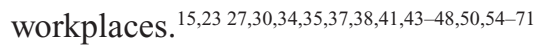

Physical interventions involved physical training, aerobics, strength training, and other physical activities with the aim of reducing psychological distress. ${ }^{19,20,22,33,43,45,47,51-53,62,63}$ Therapeutic interventions involved conventional therapies, such as cognitive/behavioral therapy, solutionfocused therapy, psychodynamic therapy, and disclosure therapy. ${ }^{19-21,24,38,42,43,54,55,57,58,64,65,70-84}$

Educational interventions refer to interventions where caregivers such as general practitioners, nurses, and social workers were educated with regard to the identification of individuals with psychological distress and psychiatric diagnoses. The caregivers were educated in guideline-based treatment and often in means to improve the individuals' adherence to treatment. ${ }^{25,26,46,48,50,54,57,58,64,65,75-77,82-90}$

Collaborative care refers to interventions which involved collaboration between different caregivers. The interventions ensured that information regarding treatment and rehabilitation was provided to different caregivers. In some studies, the effect of the intervention was monitored for each individual. If it was considered necessary, appropriate actions were taken. ${ }^{15,27,30,37,41,46-48,50,55,66,67,89,91-93}$

\section{Quality of a study}

The scientific quality of the studies was assessed by the instrument previously mentioned by Moncrieff et al. ${ }^{17}$ The items of this instrument are found in Table 2. The quality in each item was rated on a three-point Likert scale, except for some measures which were rated on a two-point Likert scale, whereby 0 indicated low quality, 1 medium quality, and 2 high quality. Two of the items in this instrument were handled differently in comparison with Moncrieff et al, ie, blinding of assessor where assessments in all cases were independent of the researcher, being based on self-report 


\begin{tabular}{|c|c|c|c|c|c|c|}
\hline \multicolumn{2}{|l|}{ Nonparticipation } & \multirow{2}{*}{$\begin{array}{l}\text { Intervention } \\
\text { Number in intervention } \\
\text { and control group }\end{array}$} & \multirow{2}{*}{$\frac{\text { Follow-up }}{\text { Nonparticipation \% }}$} & \multicolumn{3}{|l|}{ Effect } \\
\hline Target group \% & Eligible group \% & & & $\begin{array}{l}\text { Short-term } \\
<6 \text { months }\end{array}$ & $\begin{array}{l}\text { Medium-term } \\
6-12 \text { months }\end{array}$ & $\begin{array}{l}\text { Long-term } \\
12+\text { months }\end{array}$ \\
\hline \multirow[t]{2}{*}{-} & 29.8 & $S+P: 19$ & $S+P: 36.8$ & & & - \\
\hline & & CAU: 21 & CAU: 19.0 & & & \\
\hline \multirow[t]{2}{*}{33.6} & 0.0 & $E+C: 29$ & $E+C: 13.8$ & + & - & \\
\hline & & CAU: 31 & CAU: 22.6 & & & \\
\hline \multirow[t]{2}{*}{-} & 19.3 & $\mathrm{~S}+\mathrm{F}+\mathrm{T}+\mathrm{E}: 109$ & $S+F+T+E: 39.5$ & + & & + \\
\hline & & CAU: 83 & CAU: 38.9 & & & \\
\hline \multirow[t]{2}{*}{55.7} & 58.9 & $\mathrm{O}+\mathrm{F}+\mathrm{C}: 73$ & $\mathrm{O}+\mathrm{F}+\mathrm{C}: 0.0$ & - & - & \\
\hline & & CAU: 72 & CAU: 2.3 & & & \\
\hline \multirow[t]{6}{*}{48.8} & Stressed: & Stressed: & Stressed: & NC & NC & \\
\hline & P: 64.4 & P: 70 & P: 37.1 & NC & NC & \\
\hline & $\mathrm{T}: 71.2$ & $\mathrm{~T}: 57$ & $\mathrm{~T}: 2 \mathrm{I} . \mathrm{I}$ & & & \\
\hline & Nonstressed & Nonstressed: & Nonstressed: & & & \\
\hline & P: 34.8 & P: 129 & P: 44.2 & & & \\
\hline & $\mathrm{T}: 45.4$ & $\mathrm{~T}: 108$ & $\mathrm{~T}: 25.0$ & & & \\
\hline \multirow[t]{2}{*}{-} & - & F: 52 & F: 19.2 & & & + \\
\hline & & CAU: 52 & CAU: 19.2 & & & \\
\hline \multirow[t]{2}{*}{19.3} & - & $S+F+T+C: 304$ & $\mathrm{~S}+\mathrm{F}+\mathrm{T}+\mathrm{C}: \mathrm{I} 4.5$ & & + & + \\
\hline & & CAU: 300 & CAU: 10.0 & & & \\
\hline \multirow[t]{2}{*}{15.0} & 30.2 & $\mathrm{~T}+\mathrm{E}: 913$ & $T+E: 17.6$ & - & - & + \\
\hline & & CAU: 443 & CAU: 15.6 & & & \\
\hline \multirow[t]{2}{*}{9.8} & 12.4 & $\mathrm{~F}+\mathrm{T}: 5 \mathrm{I}$ & $F+T: 11.8$ & + & - & - \\
\hline & & CAU: 5I & CAU: 25.5 & & & \\
\hline 22.3 & 27.0 & E & & - & & \\
\hline
\end{tabular}

Abbreviations: $\mathrm{O}$, Organizational intervention; $\mathrm{OH}$, occupational health; $\mathrm{S}$, stress reduction; $\mathrm{F}$, feedback; $\mathrm{P}$, physical; $\mathrm{T}$, therapy; $\mathrm{E}$, education; $\mathrm{C}$, collaborative intervention; $\mathrm{CAU}$, care as usual; i, individual therapy; g, group therapy; sft, solution-focused psychotherapy; stt, short-term psychodynamic psychotherapy; Itt, long-term; at, aerobic training; st, strength training; rt, relaxation training; CMD, common mental disorders; NC, no control group.

(scored as 0 ) or register-based data (scored as 2), with side effects being omitted because the interventions were not of an intrusive nature and were not expected to impose side effects on the individuals. The studies were assessed by the author three times. In the first two reviews, each study was reviewed with regard to all items, and, in the third review, each item was assessed transversely for the studies.

\section{Target population and eligible group}

The target population was defined as the population from which the participants were recruited. The following groups of target populations were defined: the population was defined as the target population if the studies recruited individuals from the entire population; ${ }^{27,30,39,40,44,80}$ company included studies where the individuals were recruited from companies/corporations; ${ }^{28,29,31-36,38,43,49,51-53,57-59,61-69,72,79}$ primary care, ${ }^{25,26,46,48,50,73,74,76-78,81-88,90-93}$ and occupational health clinics or stress clinics refer to studies that recruited individuals who attended an occupational health clinic or stress clinic. ${ }^{15,19,20,22,24,37,41,42,45,47,54-56,60,70,71,75,89}$ Some of the occupational health/stress clinic studies recruited participants by invitation to employees in companies; however, the intervention was carried out in the context of an occupational health/stress clinic. Psychiatric refers to participants that were recruited among individuals referred to psychiatric facilities. ${ }^{21,23}$

Eligible groups of participants were defined by three criteria, ie, diagnostic criteria, criteria for level of distress measured by psychopathological rating scales, and criteria for sickness absence/return to work/retention of work. The diagnostic criteria differentiated between no diagnostic criteria, ${ }^{15,19,20,25-29,31-37,41,43,49,51-53,56-63,68,69,72,79,87,88}$ depression, ${ }^{22,23,55,66,67,74,78,82-86,91-93}$ anxiety, ${ }^{48,90}$ somatoform disorder, ${ }^{46,50,81}$ and common mental disorders. $^{21,24,30,38-40,42,44,45,47,54,64,65,70,71,73,75-77,80,89}$ Common mental disorders included single diagnostic groups, such as adjustment disorders or a mixture of common mental disorders. With regard to psychological distress criteria, a differentiation was made between plus criteria for psychological distress ${ }^{15,19,20,22-27,31,37,48,55,57-61,66,67,70,71,75-77,79,81-86,89-93}$ and no criteria for psychological distress. . $^{21,28-30,32-36,38-47,49-54,56,62-65,68,69,72-74,78,80,87,88}$ Criteria regarding sickness absence/return to work/retention of work were divided into no criteria for sickness absence/work status, ${ }^{19-22,28,29,31-36,43,46-53,55,59,61-63,68-74,76-78,81-88,90-93}$ sickness 
Table 2 Effect rates for short-term, medium-term, and long-term effects divided into quality parameters

\begin{tabular}{|c|c|c|c|c|c|c|c|}
\hline \multirow[t]{2}{*}{ Quality measures } & \multirow[t]{2}{*}{ Score } & \multicolumn{2}{|c|}{ Short-term effect } & \multicolumn{2}{|c|}{ Medium-term effect } & \multicolumn{2}{|c|}{ Long-term effect } \\
\hline & & $\begin{array}{l}\text { Number } \\
\text { of tests }\end{array}$ & $\begin{array}{l}\text { Number with } \\
\text { effect (\%) }\end{array}$ & $\begin{array}{l}\text { Number } \\
\text { of tests }\end{array}$ & $\begin{array}{l}\text { Number with } \\
\text { effect (\%) }\end{array}$ & $\begin{array}{l}\text { Number } \\
\text { of tests }\end{array}$ & $\begin{array}{l}\text { Number with } \\
\text { effect (\%) }\end{array}$ \\
\hline \multirow[t]{3}{*}{ Objectives } & 0 & 0 & $0(-)$ & 0 & $0(-)$ & 0 & $0(-)$ \\
\hline & I & 4 & I (25.0) & 5 & I (20.0) & 11 & $4(36.4)$ \\
\hline & 2 & 20 & $6(30.0)$ & 22 & $5(22.7)$ & 31 & $13(41.9)$ \\
\hline \multirow[t]{3}{*}{ Sample size } & 0 & 7 & $4(57.1)$ & 7 & I (I4.3) & 12 & $5(4 \mid .7)$ \\
\hline & 1 & 6 & I (I6.7) & 9 & $2(22.2)$ & 8 & $3(37.5)$ \\
\hline & 2 & II & $2(18.2)$ & 11 & $3(27.3)$ & 22 & $9(40.9)$ \\
\hline \multirow[t]{3}{*}{ Follow-up } & 0 & 2 & $0(0.0)$ & 0 & $0(-)$ & 0 & $0(-)$ \\
\hline & 1 & 4 & $2(50.0)$ & 7 & I (I4.3) & 0 & $0(-)$ \\
\hline & 2 & 18 & $5(27.8)$ & 20 & $5(25.0)$ & 42 & $17(40.5)$ \\
\hline \multirow[t]{3}{*}{ Power calculation } & 0 & 17 & $5(29.4)$ & 18 & $5(27.8)$ & 26 & $13(50.0)$ \\
\hline & 1 & 0 & $0(-)$ & 0 & $0(-)$ & 0 & $0(-)$ \\
\hline & 2 & 7 & $2(28.6)$ & 9 & I (II.I) & 16 & $4(25.0)$ \\
\hline \multirow[t]{3}{*}{ Allocation } & 0 & 0 & $0(-)$ & 0 & $0(-)$ & 0 & $0(-)$ \\
\hline & I & 4 & I $(25.0)$ & 4 & $2(50.0)$ & 12 & $7(58.3)$ \\
\hline & 2 & 20 & $6(30.0)$ & 23 & $4(17.4)$ & 30 & $10(33.3)$ \\
\hline \multirow[t]{2}{*}{ Concealment } & 0 & 10 & $3(30.0)$ & 10 & $3(30.0)$ & 19 & $8(42.1)$ \\
\hline & 2 & 14 & $4(28.6)$ & 17 & $3(17.6)$ & 23 & $9(39.1)$ \\
\hline \multirow[t]{3}{*}{ Treatment description } & 0 & 0 & $0(-)$ & 0 & $0(-)$ & 0 & $0(-)$ \\
\hline & I & 6 & $2(33.3)$ & 5 & I (20.0) & 14 & $5(35.7)$ \\
\hline & 2 & 18 & $5(27.8)$ & 22 & $5(22.7)$ & 28 & $12(42.9)$ \\
\hline \multirow[t]{3}{*}{ Blinding subjects } & 0 & 21 & $7(33.3)$ & 22 & $5(22.7)$ & 38 & $16(42.1)$ \\
\hline & I & 3 & $0(0.0)$ & 5 & I (20.0) & 4 & I (25.0) \\
\hline & 2 & 0 & $0(-)$ & 0 & $0(-)$ & 0 & $0(-)$ \\
\hline \multirow[t]{3}{*}{ Sample source } & 0 & 1 & I (I00.0) & 0 & $0(-)$ & 1 & $0(0.0)$ \\
\hline & I & 20 & $5(25.0)$ & 23 & $4(17.4)$ & 35 & $14(40.0)$ \\
\hline & 2 & 3 & I (33.3) & 4 & $2(50.0)$ & 6 & $3(50.0)$ \\
\hline \multirow[t]{3}{*}{ Diagnostic criteria } & 0 & 0 & $0(-)$ & 1 & I (I00.0) & 1 & I (100.0) \\
\hline & 1 & 4 & $0(0.0)$ & 4 & $0(0.0)$ & 13 & $5(38.5)$ \\
\hline & 2 & 20 & $7(35.0)$ & 22 & $5(22.7)$ & 28 & II (39.3) \\
\hline \multirow[t]{3}{*}{ Exclusions } & 0 & 1 & I (100.0) & 2 & $2(100.0)$ & 6 & $3(50.0)$ \\
\hline & 1 & 7 & $2(28.6)$ & 8 & I (I2.5) & 17 & $6(35.3)$ \\
\hline & 2 & 16 & $4(25.0)$ & 17 & $3(17.6)$ & 19 & $8(42.1)$ \\
\hline \multirow[t]{3}{*}{ Demographics } & 0 & 7 & $2(28.6)$ & 7 & $2(28.6)$ & 17 & $8(47.1)$ \\
\hline & 1 & 0 & $0(-)$ & I & I (-) & 0 & $0(-)$ \\
\hline & 2 & 17 & $5(29.4)$ & 19 & $3(15.8)$ & 25 & $9(36.0)$ \\
\hline Blinding assessor & Self & 18 & $4(22.2)$ & 18 & $3(16.7)$ & 24 & $9(37.5)$ \\
\hline & Reg & 6 & $3(50.0)$ & 9 & $3(33.3)$ & 18 & $8(44.4)$ \\
\hline Compliance & 0 & II & $6(54.5)$ & 9 & $3(33.3)$ & 22 & $9(40.9)$ \\
\hline & I & 0 & $0(-)$ & 0 & $0(-)$ & 0 & $0(-)$ \\
\hline & 2 & 13 & I (7.7) & 18 & $3(16.7)$ & 20 & $8(40.0)$ \\
\hline Withdrawals & 0 & 2 & $0(0.0)$ & 2 & I (50.0) & 5 & $2(40.0)$ \\
\hline & I & 10 & $3(30.0)$ & II & $\mathrm{I}(9.1)$ & 21 & $10(47.6)$ \\
\hline & 2 & 12 & $4(33.3)$ & 14 & $4(28.6)$ & 16 & $5(3 \mid .3)$ \\
\hline Outcome & 0 & 2 & $0(0.0)$ & 0 & $0(-)$ & 1 & $0(0.0)$ \\
\hline & 1 & 5 & $2(40.0)$ & 6 & $0(0.0)$ & 9 & $4(44.4)$ \\
\hline & 2 & 17 & $5(29.4)$ & 21 & $6(28.6)$ & 32 & $13(40.6)$ \\
\hline Comparability & 0 & 2 & I (50.0) & 1 & $0(0.0)$ & 6 & $2(33.3)$ \\
\hline & 1 & 2 & I (50.0) & 3 & I (33.3) & 5 & I (20.0) \\
\hline & 2 & 20 & $5(25.0)$ & 23 & $5(21.7)$ & 31 & 14 (45.2) \\
\hline Analysis of withdrawals & 0 & 8 & $5(62.5)$ & 5 & I (20.0) & 16 & $6(37.5)$ \\
\hline & 2 & 16 & $2(12.5)$ & 22 & $5(22.7)$ & 26 & II (42.3) \\
\hline Results & 0 & 4 & $0(0.0)$ & 4 & $2(50.0)$ & 11 & $5(45.5)$ \\
\hline & I & 17 & $7(4 \mid .2)$ & 20 & $4(20.0)$ & 23 & $8(34.8)$ \\
\hline & 2 & 3 & $0(0.0)$ & 3 & $0(0.0)$ & 8 & $4(50.0)$ \\
\hline
\end{tabular}


Table 2 (Continued)

\begin{tabular}{|c|c|c|c|c|c|c|c|}
\hline \multirow[t]{2}{*}{ Quality measures } & \multirow[t]{2}{*}{ Score } & \multicolumn{2}{|c|}{ Short-term effect } & \multicolumn{2}{|c|}{ Medium-term effect } & \multicolumn{2}{|c|}{ Long-term effect } \\
\hline & & $\begin{array}{l}\text { Number } \\
\text { of tests }\end{array}$ & $\begin{array}{l}\text { Number with } \\
\text { effect (\%) }\end{array}$ & $\begin{array}{l}\text { Number } \\
\text { of tests }\end{array}$ & $\begin{array}{l}\text { Number with } \\
\text { effect (\%) }\end{array}$ & $\begin{array}{l}\text { Number } \\
\text { of tests }\end{array}$ & $\begin{array}{l}\text { Number with } \\
\text { effect (\%) }\end{array}$ \\
\hline \multirow[t]{3}{*}{ Analysis } & 0 & 2 & $0(0.0)$ & 0 & $0(-)$ & 4 & $0(0.0)$ \\
\hline & 1 & 18 & $5(27.8)$ & 22 & $6(27.3)$ & 33 & $14(42.4)$ \\
\hline & 2 & 4 & $0(0.0)$ & 5 & $0(0.0)$ & 5 & $3(60.0)$ \\
\hline \multirow[t]{3}{*}{ Conclusions } & 0 & 0 & $0(-)$ & 0 & $0(-)$ & 0 & $0(-)$ \\
\hline & I & I & $0(-)$ & 1 & $0(0.0)$ & 4 & I $(25.0)$ \\
\hline & 2 & 23 & $7(30.4)$ & 26 & $6(23.1)$ & 38 & $16(42.1)$ \\
\hline \multirow[t]{2}{*}{ Interests } & 0 & 3 & I (33.3) & 5 & I (20.0) & 9 & $4(44.4)$ \\
\hline & 2 & 21 & $6(28.6)$ & 22 & $5(22.7)$ & 33 & $13(39.4)$ \\
\hline \multirow[t]{3}{*}{ Quality score } & $<20$ & 2 & I (50.0) & 2 & I (50.0) & 8 & $3(37.5)$ \\
\hline & $20-29$ & 7 & $2(28.6)$ & 7 & I (I4.3) & 11 & $5(45.5)$ \\
\hline & $30+$ & 15 & $4(26.7)$ & 18 & $4(22.2)$ & 23 & $9(39.1)$ \\
\hline
\end{tabular}

Quality parameters with reference to Moncrieff et al. ${ }^{17}$

absence before entry, ${ }^{15,23-27,30,37-40,42,44,45,54,57,58,64,65,75,80,89}$ and risk of sickness absence or losing contact with the labor market. $41,56,60,66,67,79$

\section{Nonparticipation}

Nonparticipation was examined in the target population, the eligible group, and at follow-up. A special case of nonparticipation from the target population is incomplete coverage which covers the situation where individuals, who were intended to be reached by the study, were not reached at all, and where it was impossible to decide which individuals were not reached..$^{94,95}$

The registration of nonparticipation from the target population and from the eligible group was restricted to individuals who refused to participate. Nonresponse from individuals who moved out of the area, died, or did not participate for other incapacitating reasons was not registered as nonparticipation.

With regard to nonparticipation at follow-up, some studies had more follow-ups, in which case the nonparticipation rate at the latest follow-up was chosen. The follow-up times varied from 3 to 36 months. The fraction of nonparticipation was registered, as well as the level of differential nonparticipation between the intervention group and the control group, and whether the differential nonparticipation was significant or not, as measured by the Chi-squared test. Some studies stated that there was no significant difference between the fraction of nonparticipation in the intervention group and in the control group. However, this could be due to the small number of participants in each group. For this reason, the $80 \%$ power limit for the intervention group was calculated as follows. The fraction of nonparticipation in the control group was kept constant, and, under this assumption, the limit of a hypothetical fraction of nonparticipation in the intervention group was calculated at $80 \%$ test power, accepting the null hypothesis that there was no significant difference between nonparticipation in the intervention group and the control group. The power tests were carried out in STATA 10.0 using the command "sampsi onesample" ${ }^{96}$ The limits shown indicate the lowest and highest integer percentage of nonparticipation nearest to but below a power of $80 \%$ at the $5 \%$ significance level. However, in one case, a power of $82 \%$ was accepted because the nearest integer nonparticipation rate with a power below $80 \%$ was as low as $66 \%$. The study data were entered into a data sheet and analyzed in STATA $10.0^{96}$ and Excel. Comparisons between groups were carried out using the Chi-squared test.

\section{Results}

Table 1 shows the 57 identified studies and illustrates the inclusion criteria, quality score, fraction of nonparticipation in the target population, the eligible group, and follow-up along with intervention type, numbers in the intervention and control groups, and effect.

\section{Effect of interventions}

Table 3 shows the figures for each intervention according to short-term, medium-term, and long-term effect rates. Overall, 30 interventions were tested for short-term effect, with an effect rate of $23.3 \%$. Stress reduction (50.0\%) showed the highest effect rate and organizational intervention $(0.0 \%)$ the lowest. Physical (25.0\%) and educational interventions $(22.2 \%)$ showed low effect rates.

\section{Medium-term effect}

In 31 interventions, the medium-term effect was tested with an overall effect rate of $19.4 \%$. Stress reduction (42.9\%) and 
Table 3 Effect rates for short-term, medium-term, and long-term effects divided into type of intervention

\begin{tabular}{|c|c|c|c|c|c|c|}
\hline \multirow[t]{2}{*}{ Intervention } & \multicolumn{2}{|c|}{ Short-term effect } & \multicolumn{2}{|c|}{ Medium-term effect } & \multicolumn{2}{|c|}{ Long-term effect } \\
\hline & $\begin{array}{l}\text { Number } \\
\text { of tests }\end{array}$ & $\begin{array}{l}\text { Number with } \\
\text { effect (\%) }\end{array}$ & $\begin{array}{l}\text { Number } \\
\text { of tests }\end{array}$ & $\begin{array}{l}\text { Number with } \\
\text { effect (\%) }\end{array}$ & $\begin{array}{l}\text { Number } \\
\text { of tests }\end{array}$ & $\begin{array}{l}\text { Number with } \\
\text { effect (\%) }\end{array}$ \\
\hline Overall & 30 & $7(23.3)$ & 31 & $6(19.4)$ & 48 & $19(39.6)$ \\
\hline Organizational & 4 & $0(0.0)$ & 4 & I (25.0) & 8 & $3(37.5)$ \\
\hline Stress reduction & 10 & $5(50.0)$ & 7 & $3(42.9)$ & 18 & $9(50.0)$ \\
\hline Feedback & 12 & $5(4 \mid .7)$ & 12 & $5(4 \mid .7)$ & 22 & $10(45.5)$ \\
\hline Physical & 4 & I (25.0) & 2 & $0(0.0)$ & 6 & $3(50.0)$ \\
\hline Therapy & 13 & $4(30.8)$ & 15 & $3(20.0)$ & 14 & $5(35.7)$ \\
\hline Education & 9 & $2(22.2)$ & 9 & $0(0.0)$ & 12 & $5(4 I .7)$ \\
\hline Collaborative care & 5 & $2(40.0)$ & 6 & $2(33.3)$ & 8 & $6(75.0)$ \\
\hline
\end{tabular}

feedback interventions (41.7\%) showed the highest effect rates, whereas physical $(0.0 \%)$ and educational interventions $(0.0 \%)$ showed the lowest.

\section{Long-term effect}

The long-term effect was tested for 48 interventions, with an overall effect rate of $39.6 \%$. The highest effect rate occurred for collaborative care interventions $(75.0 \%)$ and the lowest effect rate occurred for therapeutic interventions (35.7\%).

\section{Studies without control group}

Knekt et $\mathrm{al}^{21}$ found psychodynamic therapy superior to solution-focused therapy in the long-term effect category. Krogh et $\mathrm{al}^{22}$ found no differences in sickness absence between strength, aerobic, and relaxation training, nor for short-term, medium-term, or long-term effect. Schene et $\mathrm{al}^{23}$ found that the addition of occupational therapy to cognitive behavioral therapy significantly reduced sickness absence in the long-term effect category. Stenlund et $\mathrm{al}^{24}$ compared the effect of cognitive therapy including Qigong (stress reduction) with cognitive therapy alone and found no differences in medium-term and long-term effects. van Rhenen et al ${ }^{19,20}$ found no difference between cognitive behavioral therapy compared with physical exercise with regard to short-term and medium-term effect.

\section{Effect related to scientific quality of studies}

Table 2 shows the number of studies and quality measures divided by short-term, medium-term, and long-term effect. In the interpretation of this table, it must be borne in mind that the number of tests in several cells is low. With regard to the quality of the studies, most of the studies showed a similar pattern, whether it concerned short-term, medium-term, or long-term effect. The studies showed good quality in the majority of the quality items. The exceptions were sample source, results, and analysis, in which the majority of studies were of medium quality, and for power calculation, blinding of subjects, and blinding of subjects (self-report), the studies were of low quality. With regard to quality score, a large part of the studies had a score of $\geq 30$.

\section{Short-term effect}

Two quality parameters, ie, compliance $(54.5 \%, P=0.012)$ and analysis of withdrawals $(62.5 \%, P=0.011)$, showed significantly higher effect rates for studies of low quality compared with studies of medium or high quality. Sample size (57.1\%) and blinding of subjects (33.3\%) also showed relatively high effect rates, but nonsignificantly for studies of low quality. With regard to medium quality, follow-up (50.0\%), outcome $(40.0 \%)$, comparability $(50.0 \%)$, results $(41.2 \%)$, and analysis $(27.8 \%)$ showed the highest effect rates, and for high-quality studies, the highest effect rates occurred for diagnostic criteria (35.0\%) and blinding of assessor (50.0\%). With regard to the quality score, the studies with the lowest quality (score $<20$ ) had the highest effect rate $(50.0 \%)$.

\section{Medium-term effect}

One test, exclusions $(100.0 \%, P=0.022)$, showed a significantly higher effect rate for low quality than for medium and high quality studies. Power calculation (27.8\%), concealment (30.0\%), exclusions (100.0\%), demographics (28.6\%), compliance $(33.3 \%)$, withdrawals $(50.0 \%)$, and results $(50.0 \%)$ also showed relatively high effect rates with regard to low quality, but nonsignificantly. For medium quality, the highest effect rates (nonsignificantly) occurred for allocation (50.0\%), comparability (33.3\%), and analysis (27.3\%). For high quality, the highest success rates (nonsignificantly) occurred for sample source $(50.0 \%)$, blinding of assessor (33.3\%), outcome (28.6\%), and conclusions (23.1\%). With regard to quality score, studies with the lowest quality $($ score $<20)$ had the highest effect rate $(50.0 \%)$. 


\section{Long-term effect}

There were no significant differences for the long-term effect category. Power calculation (50.0\%) and blinding of subjects (42.1\%) showed, nonsignificantly, higher effect rates for low quality compared with medium and high quality. For allocation $(58.3 \%)$ and withdrawals (47.6\%), the highest success rates were seen for medium quality and for high quality of sample source $(50.0 \%)$, analysis $(60.0 \%)$, and conclusions $(42.1 \%)$. There were no differences with regard to the quality score.

\section{Effect related to inclusion criteria}

Table 4 shows the number of studies and inclusion criteria divided by short-term, medium-term, and long-term effect.

\section{Short-term effect}

An inclusion diagnosis of common mental disorders (63.6\%, $P=0.001)$ had a significantly higher effect rate than no diagnosis or other inclusion diagnoses. Population (66.7\%) plus criteria for psychological distress $(41.7 \%)$ and sickness absence before entry (41.7\%) showed relatively high effect rates, but not significantly so.

\section{Medium-term effect}

There were no significant differences for medium-term effect. Population (66.7\%), depression (33.3\%), no criteria for psychological distress (30.8\%), and no criteria for sickness absence/work status (28.6\%) showed relatively high but nonsignificant effect rates.

\section{Long-term effect}

There were no significant differences. The highest, but nonsignificant, effect rates occurred for primary care (44.4\%), occupational health/stress clinic (44.4\%), depression $(80.0 \%)$, no criteria for psychological distress $(44.0 \%)$, and no criteria for sickness absence/work status (46.2\%).

\section{Effect related to nonparticipation}

Table 5 shows the number of studies and nonparticipation parameters divided by short-term, medium-term, and long-term effect. It was possible that incomplete coverage occurred in $25(44 \%)$ of the studies, because the size of the target population could not be estimated. The total nonparticipation rate for the target population was more than $30 \%$ in 15 (26\%) studies. The nonparticipation rate for eligible participants was unknown in eight (14\%) of the studies, and the nonparticipation rate was more than $30 \%$ in $17(30 \%)$ of the studies. At follow-up, it was possible to estimate the nonparticipation rate in 63 intervention groups, in which the nonparticipation rate was higher than $30 \%$ in $14(22 \%)$ studies and in 47 control groups. Of the 47 control groups, the nonparticipation rate was higher than $30 \%$ in 10 (21\%) studies. Measures for differential nonparticipation at follow-up could be tested in 59 tests. Differential nonparticipation was below $10 \%$ in $40(68 \%)$ tests, $10 \%-20 \%$ in $16(27 \%)$ tests, and $20 \%$ or higher in three $(5 \%)$ tests. The hypothetical level of nonparticipation at $80 \%$ power limit

Table 4 Effect rates for short-term, medium-term, and long-term effects divided by inclusion criteria

\begin{tabular}{|c|c|c|c|c|c|c|}
\hline \multirow[t]{2}{*}{ Inclusion criteria } & \multicolumn{2}{|c|}{ Short-term effect } & \multicolumn{2}{|c|}{ Medium-term effect } & \multicolumn{2}{|c|}{ Long-term effect } \\
\hline & $\begin{array}{l}\text { Number } \\
\text { of tests }\end{array}$ & $\begin{array}{l}\text { Number with } \\
\text { effect (\%) }\end{array}$ & $\begin{array}{l}\text { Number } \\
\text { of tests }\end{array}$ & $\begin{array}{l}\text { Number with } \\
\text { effect (\%) }\end{array}$ & $\begin{array}{l}\text { Number } \\
\text { of tests }\end{array}$ & $\begin{array}{l}\text { Number with } \\
\text { effect (\%) }\end{array}$ \\
\hline \multicolumn{7}{|l|}{ Target population } \\
\hline Population & 3 & $2(66.7)$ & 3 & $2(66.7)$ & 5 & $2(40.0)$ \\
\hline Company & 5 & I (20.0) & 7 & $2(28.6)$ & 19 & $7(36.8)$ \\
\hline Primary care & 7 & $0(0.0)$ & 8 & I (12.5) & 9 & $4(44.4)$ \\
\hline Occupation health/stress clinic & 9 & $4(44.4)$ & 9 & I (II.I) & 8 & $4(44.4)$ \\
\hline \multicolumn{7}{|l|}{ Inclusion diagnosis } \\
\hline No diagnosis & 7 & $0(0.0)$ & 10 & $2(20.0)$ & 23 & $8(34.8)$ \\
\hline Depression & 4 & $0(0.0)$ & 6 & $2(33.3)$ & 5 & $4(80.0)$ \\
\hline Anxiety & I & $0(0.0)$ & 0 & $0(-)$ & I & I (I00.0) \\
\hline Somatoform disorder & I & $0(0.0)$ & I & $0(0.0)$ & 2 & $0(0.0)$ \\
\hline Common mental disorders & II & $7(63.6)$ & 10 & $2(20.0)$ & II & $4(36.4)$ \\
\hline \multicolumn{7}{|l|}{ Psychopathological score } \\
\hline No & 12 & $5(4 I .7)$ & 13 & $4(30.8)$ & 25 & II (44.0) \\
\hline Yes & 12 & $2(16.7)$ & 14 & $2(14.3)$ & 17 & $6(35.3)$ \\
\hline \multicolumn{7}{|l|}{ Sickness absence/work status } \\
\hline No criteria & II & $2(18.2)$ & 14 & $4(28.6)$ & 26 & $12(46.2)$ \\
\hline Plus sickness absence & 12 & $5(4 I .7)$ & 11 & $2(18.2)$ & 11 & $3(27.3)$ \\
\hline $\begin{array}{l}\text { Risk of sickness absence/return } \\
\text { to/retention of work }\end{array}$ & I & $0(0.0)$ & 2 & $0(0.0)$ & 5 & $2(40.0)$ \\
\hline
\end{tabular}


Table 5 Effect rates for short-term, medium-term, and long-term effects divided by nonparticipation parameters

\begin{tabular}{|c|c|c|c|c|c|c|}
\hline \multirow[t]{2}{*}{ Intervention } & \multicolumn{2}{|c|}{ Short-term effect } & \multicolumn{2}{|c|}{ Medium-term effect } & \multicolumn{2}{|c|}{ Long-term effect } \\
\hline & $\begin{array}{l}\text { Number } \\
\text { of tests }\end{array}$ & $\begin{array}{l}\text { Number with } \\
\text { effect (\%) }\end{array}$ & $\begin{array}{l}\text { Number } \\
\text { of tests }\end{array}$ & $\begin{array}{l}\text { Number with } \\
\text { effect (\%) }\end{array}$ & $\begin{array}{l}\text { Number } \\
\text { of tests }\end{array}$ & $\begin{array}{l}\text { Number with } \\
\text { effect (\%) }\end{array}$ \\
\hline \multicolumn{7}{|c|}{ Nonparticipation in target group \% } \\
\hline Missing & 10 & $4(10.0)$ & 7 & $0(0.0)$ & 19 & $7(36.8)$ \\
\hline$<25$ & 8 & $2(25.0)$ & 11 & $3(27.3)$ & II & $5(45.5)$ \\
\hline $25-50$ & 4 & I (25.0) & 4 & I (25.0) & 5 & $2(40.0)$ \\
\hline $50+$ & 2 & $0(0.0)$ & 5 & $2(40.0)$ & 7 & $3(42.9)$ \\
\hline \multicolumn{7}{|c|}{ Nonparticipation in eligible group \% } \\
\hline Missing & 0 & $0(-)$ & 3 & $2(66.7)$ & 6 & $4(66.7)$ \\
\hline$<25$ & 12 & $6(50.0)$ & 10 & $2(20.0)$ & 19 & $6(31.6)$ \\
\hline $25-50$ & 8 & $0(0.0)$ & 9 & $2(22.2)$ & 13 & $7(53.8)$ \\
\hline $50+$ & 4 & I (25.0) & 5 & $0(0.0)$ & 4 & $0(0.0)$ \\
\hline \multicolumn{7}{|c|}{ Number in inclusion group } \\
\hline Missing & I & $0(0.0)$ & 0 & $0(-)$ & I & I (I00.0) \\
\hline$<50$ & 7 & $4(57.1)$ & 8 & $\mathrm{I}(12.5)$ & 9 & $2(22.2)$ \\
\hline $50<100$ & 12 & $2(16.7)$ & 15 & $2(13.3)$ & 16 & $5(3 \mid .3)$ \\
\hline $100+$ & 10 & $2(20.0)$ & 9 & $3(33.3)$ & 22 & II(50.0) \\
\hline \multicolumn{7}{|c|}{ Follow-up: nonparticipation in inclusion group (\%) } \\
\hline Missing & 3 & $0(0.0)$ & 3 & I (33.3) & 6 & $2(33.3)$ \\
\hline$<10$ & 6 & $2(33.3)$ & 7 & I (I4.3) & 13 & $5(38.5)$ \\
\hline $10-20$ & 10 & $3(30.0)$ & 11 & $2(18.2)$ & 14 & $7(50.0)$ \\
\hline $20+$ & II & $3(27.3)$ & II & I (9.1) & 14 & $5(35.7)$ \\
\hline \multicolumn{7}{|c|}{ Number in control group (\%) } \\
\hline Missing & 1 & $0(0.0)$ & I & $0(0.0)$ & I & I (I00.0) \\
\hline$<50$ & 7 & $4(57.1)$ & 5 & $0(0.0)$ & 8 & $2(25.0)$ \\
\hline $50-100$ & 9 & $2(22.2)$ & 12 & I (8.3) & 14 & $5(35.7)$ \\
\hline $100+$ & 8 & I (I2.5) & 11 & $5(45.5)$ & 21 & $10(47.6)$ \\
\hline \multicolumn{7}{|c|}{ Follow-up: nonparticipation in control group (\%) } \\
\hline Missing & 3 & $0(0.0)$ & 3 & I (33.3) & 6 & $2(33.3)$ \\
\hline$<10$ & 4 & I (25.0) & 6 & I (I6.7) & 10 & $3(30.0)$ \\
\hline $10-20$ & 9 & $2(22.2)$ & 9 & $2(22.2)$ & 17 & $7(4 \mid .2)$ \\
\hline $20+$ & 9 & $4(44.4)$ & 10 & $2(20.0)$ & II & $5(45.5)$ \\
\hline \multicolumn{7}{|c|}{ Difference in nonparticipation between inclusion and control group (\%) } \\
\hline Missing & 3 & $0(0.0)$ & 3 & I (33.3) & 6 & $2(33.3)$ \\
\hline$<10$ & 19 & $6(31.6)$ & 22 & $4(18.2)$ & 29 & $15(51.7)$ \\
\hline $10-20$ & 7 & $2(28.6)$ & 5 & I (20.0) & II & $2(18.2)$ \\
\hline $20+$ & 1 & $0(0.0)$ & 2 & $0(0.0)$ & 1 & $0(0.0)$ \\
\hline \multicolumn{7}{|c|}{$80 \%$ power limits in difference in nonparticipation between inclusion and control group (\%) } \\
\hline Missing & 3 & $0(0.0)$ & 3 & I (33.3) & 6 & $2(33.3)$ \\
\hline$<10$ & 10 & $I(10.0)$ & 13 & $2(15.4)$ & 21 & $10(47.6)$ \\
\hline $10-20$ & 11 & $3(27.3)$ & 11 & $3(27.2)$ & 18 & $7(38.9)$ \\
\hline $20+$ & 6 & $4(66.7)$ & 5 & $0(0.0)$ & 2 & $0(0.0)$ \\
\hline \multicolumn{7}{|c|}{ Significance in differential nonparticipation between intervention and control group (\%) } \\
\hline Missing & 3 & $0(0.0)$ & 3 & I (33.3) & 6 & $2(33.3)$ \\
\hline Yes & 6 & I (I6.7) & 4 & I $(25.0)$ & 8 & $3(37.5)$ \\
\hline No & 21 & $7(33.3)$ & 25 & $4(16.0)$ & 33 & I4 (42.4) \\
\hline
\end{tabular}

was below $10 \%$ in $25(42 \%)$ tests, $10 \%-20 \%$ in $26(44 \%)$ tests, and $20 \%$ or more in eight $(14 \%)$ tests. Differential nonparticipation was significant in $10(17 \%)$ tests.

\section{Short-term effect}

The highest, nonsignificant, effect rates occurred for nonparticipation in the target population of $0 \%-50 \%$
$(25.0 \%)$, for nonparticipation in the eligible group of $0 \%-25 \%(50.0 \%)$, number in inclusion group of $0-50$ participants $(57.1 \%)$, number in control group of $0-50$ participants $(57.1 \%)$, nonparticipation in control group at follow-up $20 \%$ or higher of $44.4 \%, 80 \%$ power limit, $20 \%$ or more of $66.7 \%$, and no significance in differential nonparticipation $(33.3 \%)$. 


\section{Medium-term effect}

For medium effect, the highest, nonsignificant, effect rates occurred for nonparticipation in the target population of $50 \%$ or higher $(40.0 \%)$, missing information regarding nonparticipation in the eligible group of $66.7 \%$, number of participants in the inclusion group of 100 or more (33.3\%), number of participants in the control group of 100 or more $(45.5 \%)$, missing information regarding nonparticipation in control group at follow-up of $33.3 \%$, missing information regarding differential nonparticipation of $33.3 \%$, missing information regarding $80 \%$ power limit of $33.3 \%$, and missing information regarding significance in differential nonparticipation of $33.3 \%$.

\section{Long-term effect}

For long-term effect, there was a tendency toward smaller differences with regard to differential nonparticipation. However, there were tendencies toward nonsignificant higher effect rates for missing information regarding nonparticipation in the eligible group (66.7\%), number of participants in the intervention group -100 or more $(50.0 \%)$, non-participation in the intervention group $-10 \%$ to $20 \%(50.0 \%)$, and Differential non-participation $-0 \%$ to $10 \%(51.7 \%)$.

\section{Discussion}

The burden imposed by mental disorders has motivated clinicians, rehabilitation officers, and researchers to identify risk factors for sickness absence and factors affecting people's ability to work. In a review by Beauregard et al, ${ }^{97}$ it is stated that several key factors with regard to the psychosocial work environment (eg, decision latitude, psychological demands, social support, and rewards) have been identified with regard to causing deterioration of workers' mental health. Much less attention has been paid to the significance of other pivotal life environments than to the psychosocial work environment. Overall, there was insufficient evidence of any effect on workers' mental health by family or community/society level factors, except that an effect of moderate significance was found for social support at the work level. Other studies have identified other predictors such as those presented in a review by Blank et al ${ }^{98}$ who found that successful return to work was predicted by factors related to work as well as factors related to family history, health risk behaviors, social status, and medical condition. Cornelius et a ${ }^{199}$ found strong evidence that older age ( $>50$ years) is associated with longer time taken to return to work. In addition, limited evidence was found for other personal, sociodemographic, and health-related and external work-related factors. It is also well documented that comorbidity is significantly associated with role impairment, ${ }^{5,100-114}$ and Franche and Krause ${ }^{115}$ have documented that return to work is influenced by the complex concept of motivation.

Several interventions aiming to reduce sickness absence and to improve work status have been the subjects of trials and reviews. The multifactorial reasons mentioned above for long-term sickness absence and restraints for improving work status have been a challenge for reviewers. The plenitude of factors involved imposes an abundance of interventions, differences in target groups, and inclusion criteria. In reviews, specific criteria are applied to these factors, thereby delimiting the number of included studies. In addition, criteria for the scientific quality of the studies reduce the number of studies further. The final result often demonstrates limited evidence.

Some reviews have focused particularly on screening for mental disorders, primarily in primary care and nonspecialist settings. ${ }^{9,10,12}$ Gilbody et $\mathrm{al}^{9}$ found a minimal impact of screening on the detection of mental disorders. Hickie et al ${ }^{10}$ concluded that screening increases the detection and diagnosis of depression and, when integrated with a commitment to provide a coordinated, prompt follow-up on diagnosis and treatment, clinical outcomes are improved. Pignone et $\mathrm{al}^{12}$ concluded that screening combined with feedback to caregivers increased detection of depressive illness, and, furthermore, reduced the risk of persistent depression. Programs which integrated interventions with quality improvements in clinical systems showed a more significant effect than programs consisting of feedback alone. The reviews did not address the effect on sickness absence.

Other reviews have addressed the effects of therapeutic interventions. These reviews showed promising effects for cognitive behavioral therapy and multimodal and collaborative care. ${ }^{11,13,14,16,116} \mathrm{~A}$ meta-analyses by van der Klink et al, ${ }^{14}$ in which 48 studies were included, provided significant effect sizes of 0.68 for cognitive behavioral therapy, 0.51 for multimodal programs, and 0.35 for relaxation techniques, whereas the effect size for organization-focused interventions was nonsignificant at 0.08 . The effects were mostly noticeable in terms of complaints, psychological measures, and perceived quality of life.

The reviews hardly provide information about sickness absence and return to work/retention of work. ${ }^{11,13,14,16,116} \mathrm{In}$ the meta-analysis by van der Klink et al, ${ }^{14}$ outcome measures for sickness absence or return to work were only provided for seven out of 48 studies. Seven studies did not show any effect on the outcome parameters. 
The overall conclusion of this study is that the effect rate was low, about $20 \%$ for short-term (up to 6 months) effect and medium-term (6-12 months), and $40 \%$ for long-term (12 months and longer) effect. It is promising that the effect rate was higher for long-term effect than for the shorterterm effects. Interventions applying stress reduction were most effective with regard to short-term and medium-term effects, whereas collaborative care was most effective for long-term effect. Organizational, therapeutic, and physical interventions had the lowest short-term effect, where physical and therapeutic interventions had the lowest medium-term effect and therapeutic interventions the lowest long-term effect. With regard to inclusion criteria, the most noticeable result was that inclusion criteria for common mental disorders had a significantly higher short-term effect rate. With regard to quality measures of the studies, the results ought to be analyzed cautiously because many cells in the analysis contained few studies and plenty of comparisons were carried out. Consequently, the results may have occurred by chance. There seems to be a tendency for the highest effect rates to have occurred in studies with the lowest quality for power calculation, compliance, analysis of withdrawals, blinding of subjects, and low quality score. High effect rates were seen for studies of medium quality for allocation, and studies of high quality with regard to blinding of assessor (register-based outcome data), and conclusions. With regard to the nonparticipation parameters, no definite trends could be identified.

Stress reduction was effective in the short-term effect category, which was also seen for no criteria for psychological distress in the inclusion criteria. The two measures were closely related to each other. Furthermore, stress reduction interventions were primarily offered in population samples. The effect on stress reduction is in accordance with a review by Saunders et al ${ }^{117}$ documenting the effect of stress inoculation training for individuals with anxiety, and consistent with a review by Martin et $\mathrm{al}^{118}$ showing the effect of healthpromoting and stress-reducing interventions in workplaces. However, the effect sizes were minor.

In accordance with the previously mentioned reviews, collaborative care was the most effective intervention measure with regard to long-term effect. ${ }^{11,13,14,16,116}$ However, in contrast with the same reviews, which showed a positive effect for cognitive behavioral therapy, low effect was seen for therapy in this study. An explanation may be that there is a gap between improvement of the psychological distress and return to work. Factors other than mental health may be linked with the return to work process. In this process factors are addressed in the collaborative care interventions but not in the therapeutic therapies. The study indicated that in studies of low scientific quality, higher effect rates were likely with regard to the quality factors of compliance, analysis of withdrawals, and exclusions. Consequently, this study partly supports the study by Moher et $\mathrm{al}^{18}$ which demonstrated that the overall quality of a study predicted the obtained effect size.

\section{Study limitations}

One limitation may be that the literature search was restricted to PubMed (Medline), Embase, and PsycINFO. The inclusion of more databases may have yielded additional studies. However, most of the studies were identified by PubMed. The search criteria in the field of sickness absence are not very specific, which is reflected in the fact that several studies were identified by browsing.

Another limitation is the fact that the studies were only evaluated by the author. Reviews by additional reviewers would have been preferable; however, this was not possible. The fact that the studies were reviewed three times; in the first two reviews, each study with regard to all items, and in the third review, each item transversely, secures the consistency of the evaluation, although not a biased evaluation by the reviewer.

The study involved plenty of comparisons between groups, yielding a few significant results for which reason the results may have evolved by chance. In addition, the many variables may interact with each other, which could have been overcome by multivariate analyses. However, the low number of studies made this impossible, and also made it impossible to compare the effects of combined interventions with those of single interventions.

\section{Conclusion}

The overall conclusion is that the effect rate was low, ie, about $20 \%$ for short-term (up to 6 months) effect and medium-term (6-12 months) effect, and 40\% for long-term ( $\geq 12$ months) effect. It is promising that long-term effects were the highest. Interventions applying stress reduction were most effective with regard to short-term and medium-term effects, whereas collaborative care was more effective than others for longterm effect. It was remarkable that therapies do not have an effect on sickness absence and return to work, which is in contrast with the effect of psychological and quality of life parameters found in other studies. This indicates a gap between a subjective positive effect on mental health and being active in the labor market, which is a matter for 
future studies. There is a need for future large-scale studies of high methodological quality, such as the Danish national return-to-work program. ${ }^{119}$ The outcome parameters ought to be standardized, as proposed by Hensing. ${ }^{120}$

\section{Disclosure}

The author reports no conflicts of interest in this work.

\section{References}

1. Andlin-Sobocki P, Jonsson B, Wittchen HU, Olesen J. Cost of disorders of the brain in Europe. Eur J Neurol. 2005;12 Suppl 1:1-27.

2. Hiller W, Rief W, Fichter MM. How disabled are patients with somatoform disorders? Gen Hosp Psychiatry. 1997;19(6):432-438

3. Cassano P, Fava M. Depression and public health: an overview. $J$ Psychosom Res. 2002;53(4):849-857.

4. Sobieraj M, Williams J, Marley J, Ryan P. The impact of depression on the physical health of family members. Br J Gen Pract. 1998; 48(435):1653-1655.

5. Kessler RC, Ormel J, Demler O, Stang PE. Comorbid mental disorders account for the role impairment of commonly occurring chronic physical disorders: results from the National Comorbidity Survey. J Occup Environ Med. 2003;45(12):1257-1266.

6. Organization for Economic Cooperation and Development. Sickness, disability and work: keeping on track in the economic downturn-background paper, 2009. Available from: www.oecd.org/dataoecd/42/15/42699911. pdf. Accessed March 21, 2012.

7. Soegaard HJ, Bech P. Psychiatric disorders in long-term sickness absence - a population based cross-sectional study. Scand J Public Health. 2009;37(7):682-689.

8. Hensing G, Andersson L, Brage S. Increase in sickness absence with psychiatric diagnosis in Norway: a general population-based epidemiologic study of age, gender and regional distribution. BMC Med. 2006;4:19.

9. Gilbody S, House AO, Sheldon TA. Screening and case finding instruments for depression. Cochrane Database Syst Rev. 2005; 4:CD002792.

10. Hickie IB, Davenport TA, Ricci CS. Screening for depression in general practice and related medical settings. Med J Aust. 2002; Suppl 177:S111-S116.

11. Nieuwenhuijsen K, Bültmann U, Neumeyer-Gromen A, NeumeyerGromen A, Verbeek J, van der Feltz-Cornelis C. Interventions to improve occupational health in depressed people. Cochrane Database Syst Rev. 2008;2:CD006237.

12. Pignone MP, Gaynes BN, Rushton JL, et al. Screening for depression in adults: a summary of the evidence for the U.S. Preventive Services Task Force. Ann Intern Med. 2002;136(10):765-776.

13. Ruotsalainen JH, Verbeek JH. Preventing occupational stress in health care workers. Cochrane Database Syst Rev. 2009;4:1-43.

14. van der Klink JJ, Blonk RW, Schene AH, van Dijk FJ. The benefits of interventions for work-related stress. Am J Public Health. 2001;91(2):270-276.

15. van Oostrom SH, Heymans MW, de Vet HC, van Tulder MW, van Mechelen W, Anema JR. Economic evaluation of a workplace intervention for sick-listed employees with distress. Occup Environ Med. 2010;67(9):603-610.

16. van Oostrom SH, Driessen MT, de Vet HCW, et al. Workplace interventions for preventing work disability. Cochrane Database Syst Rev. 2009;2:CD006955

17. Moncrieff J, Churchill R, Drummond DC, McGuire H. Development of a quality assessment instrument for trials of treatments for depression and neurosis. Int J Methods Psychiatr Res. 2001;10(3):126-133.

18. Moher D, Pham B, Jones A, et al. Does quality of reports of randomised trials affect estimates of intervention efficacy reported in meta-analyses? Lancet. 1998;352(9128):609-613.
19. van Rhenen W, Blonk RW, van der Klink JJ, van Dijk FJ, Schaufeli WB. The effect of a cognitive and a physical stress-reducing programme on psychological complaints. Int Arch Occup Environ Health. 2005;78(2):139-148.

20. van Rhenen W, Blonk RW, Schaufeli WB, van Dijk FJ. Can sickness absence be reduced by stress reduction programs: on the effectiveness of two approaches. Int Arch Occup Environ Health. 2007; 80(6):505-515.

21. Knekt P, Lindfors O, Laaksonen MA, Raitasalo R, Haaramo P, Jarvikoski A. Effectiveness of short-term and long-term psychotherapy on work ability and functional capacity - a randomized clinical trial on depressive and anxiety disorders. J Affect Disord. 2008;107(1-3):95-106.

22. Krogh J, Saltin B, Gluud C, Nordentoft M. The DEMO trial: a randomized, parallel-group, observer-blinded clinical trial of strength versus aerobic versus relaxation training for patients with mild to moderate depression. J Clin Psychiatry. 2009;70(6):790-800.

23. Schene AH, Koeter MW, Kikkert MJ, Swinkels JA, McCrone P. Adjuvant occupational therapy for work-related major depression works: randomized trial including economic evaluation. Psychol Med. 2007;37(3):351-362.

24. Stenlund T, Ahlgren C, Lindahl B, et al. Cognitively oriented behavioral rehabilitation in combination with Qigong for patients on long-term sick leave because of burnout: REST - a randomized clinical trial. Int J Behav Med. 2009;16(3):294-303.

25. Bakker IM, Terluin B, van Marwijk HW, et al. A cluster-randomised trial evaluating an intervention for patients with stress-related mental disorders and sick leave in primary care. PLoS Clin Trials. 2007;2(6):e26.

26. Uegaki K, Bakker I, de Bruijne M, et al. Cost-effectiveness of a minimal intervention for stress-related sick leave in general practice: results of an economic evaluation alongside a pragmatic randomised control trial. J Affect Disord. 2010;120(1-3):177-187.

27. Soegaard HJ, Bech P. The effect on length of sickness absence by recognition of undetected psychiatric disorder in long-term sickness absence. A randomized controlled trial. Scand J Public Health. 2009;37(8):864-871.

28. Bond FW, Bunce D. Job control mediates change in a work reorganization intervention for stress reduction. $J$ Occup Health Psychol. 2001;6(4):290-302.

29. Boumans NP, Landeweerd JA. Nurses' well-being in a primary nursing care setting in The Netherlands. Scand J Caring Sci. 1999; 13(2):116-122.

30. Karlson B, Jonsson P, Palsson B, et al. Return to work after a workplaceoriented intervention for patients on sick-leave for burnout - a prospective controlled study. BMC Public Health. 2010;10:301.

31. Kawakami N, Araki S, Kawashima M, Masumoto T, Hayashi T. Effects of work-related stress reduction on depressive symptoms among Japanese blue-collar workers. Scand J Work Environ Health. 1997;23(1):54-59.

32. Kobayashi Y, Kaneyoshi A, Yokota A, Kawakami N. Effects of a worker participatory program for improving work environments on job stressors and mental health among workers: a controlled trial. J Occup Health. 2008;50(6):455-470.

33. Maes S, Verhoeven C, Kittel F, Scholten H. Effects of a Dutch work-site wellness-health program: the Brabantia project. Am J Public Health. 1998;88(7):1037-1041.

34. Munz DC, Kohler JM, Greenberg CI. Effectiveness of a comprehensive worksite stress management program: combining organizational and individual interventions. Int J Stress Manage. 2001;8(1):49-62.

35. Reynolds S. Psychological well-being at work: is prevention better than cure? J Psychosom Res. 1997;43(1):93-102.

36. Schrijnemaekers VJ, van Rossum E, Candel MJ, et al. Effects of emotion-oriented care on work-related outcomes of professional caregivers in homes for elderly persons. J Gerontol B Psychol Sci Soc Sci. 2003;58(1):S50-S57.

37. van Oostrom SH, van Mechelen W, Terluin B, de Vet HC, Knol DL, Anema JR. A workplace intervention for sick-listed employees with distress: results of a randomised controlled trial. Occup Environ Med. 2010;67(9):596-602. 
38. Blonk RW, Brenninkmeijer V, Lagerveld SE, Houtman I. Return to work: a comparison of two cognitive behavioural interventions in cases of work-related psychological complaints among self-employed. Work and Stress. 2006;20(2):129-144.

39. Brattberg G. Internet-based rehabilitation for individuals with chronic pain and burnout: a randomized trial. Int J Rehabil Res. 2006;29(3):221-227.

40. Brattberg G. Internet-based rehabilitation for individuals with chronic pain and burnout II: a long-term follow-up. Int $J$ Rehabil Res. 2007;30(3):231-234.

41. de Boer AG, van Beek JC, Durinck J, Verbeek JH, van Dijk FJ. An occupational health intervention programme for workers at risk for early retirement; a randomised controlled trial. Occup Environ Med. 2004;61(11):924-929.

42. de Vente W, Kamphuis JH, Emmelkamp PM, Blonk RW. Individual and group cognitive-behavioral treatment for work-related stress complaints and sickness absence: a randomized controlled trial. J Occup Health Psychol. 2008;13(3):214-231.

43. Eriksen HR, Ihlebaek C, Mikkelsen A, Gronningsaeter H, Sandal GM, Ursin H. Improving subjective health at the worksite: a randomized controlled trial of stress management training, physical exercise and an integrated health programme. Occup Med (Lond). 2002;52(7): 383-391.

44. Fleten N, Johnsen R. Reducing sick leave by minimal postal intervention; a randomized, controlled intervention study. Occup Environ Med. 2006;63(10):676-682.

45. Grossi G, Santell B. Quasi-experimental evaluation of a stress management programme for female county and municipal employees on long-term sick leave due to work-related psychological complaints. J Rehabil Med. 2009;41(8):632-638.

46. Luo Z, Goddeeris J, Gardiner JC, Smith RC. Costs of an intervention for primary care patients with medically unexplained symptoms: a randomized controlled trial. Psychiatr Serv. 2007;58(8): 1079-1086.

47. Netterstrom B, Bech P. Effect of a multidisciplinary stress treatment programme on the return to work rate for persons with work-related stress. A nonrandomized controlled study from a stress clinic. $B M C$ Public Health. 2010;10:658.

48. Rollman BL, Belnap BH, Mazumdar S, et al. A randomized trial to improve the quality of treatment for panic and generalized anxiety disorders in primary care. Arch Gen Psychiatry. 2005;62(12): 1332-1341

49. Saksvik PO, Nytro K. Improving subjective health and reducing absenteeism in a natural work life-intervention. Scand J Psychol. 2001;42(1):17-24.

50. Smith RC, Lyles JS, Gardiner JC, et al. Primary care clinicians treat patients with medically unexplained symptoms: a randomized controlled trial. J Gen Intern Med. 2006;21(7):671-677.

51. Svensson AL, Stroyer J, Ebbehoj NE, et al. Multidimensional intervention and sickness absence in assistant nursing students. Occup Med (Lond). 2009;59(8):563-569.

52. Svensson AL, Marott JL, Suadicani P, Mortensen OS, Ebbehoj NE. Sickness absence in student nursing assistants following a preventive intervention programme. Occup Med (Lond). 2011;61(1):57-61.

53. Tveito TH, Eriksen HR. Integrated health programme: a workplace randomized controlled trial. $J$ Adv Nurs. 2009;65(1):110-119.

54. van der Klink JJ, Blonk RW, Schene AH, van Dijk FJ. Reducing long term sickness absence by an activating intervention in adjustment disorders: a cluster randomised controlled design. Occup Environ Med. 2003;60(6):429-437.

55. Wang PS, Simon GE, Avorn J, et al. Telephone screening, outreach, and care management for depressed workers and impact on clinical and work productivity outcomes: a randomized controlled trial. JAMA. 2007;298(12):1401-1411.

56. Bonde JP, Rasmussen MS, Hjollund $\mathrm{H}$, et al. Occupational disorders and return to work: a randomized controlled study. J Rehabil Med. 2005;37(4):230-235.
57. Brouwers EP, Tiemens BG, Terluin B, Verhaak PF. Effectiveness of an intervention to reduce sickness absence in patients with emotional distress or minor mental disorders: a randomized controlled effectiveness trial. Gen Hosp Psychiatry. 2006;28(3):223-229.

58. Brouwers EP, de Bruijne MC, Terluin B, Tiemens BG, Verhaak PF. Cost-effectiveness of an activating intervention by social workers for patients with minor mental disorders on sick leave: a randomized controlled trial. Eur J Public Health. 2007;17(2): 214-220.

59. Duijts SF, Kant I, van den Brandt PA, Swaen GM. Effectiveness of a preventive coaching intervention for employees at risk for sickness absence due to psychosocial health complaints: results of a randomized controlled trial. J Occup Environ Med. 2008;50(7): 765-776.

60. Kant I, Jansen NW, van Amelsvoort LG, van Leusden R, Berkouwer A. Structured early consultation with the occupational physician reduces sickness absence among office workers at high risk for long-term sickness absence: a randomized controlled trial. J Occup Rehabil. 2008;18(1):79-86.

61. Kawakami N, Haratani T, Iwata N, Imanaka Y, Murata K, Araki S. Effects of mailed advice on stress reduction among employees in Japan: a randomized controlled trial. Ind Health. 1999;37(2): 237-242.

62. Proper KI, de Bruyne MC, Hildebrandt VH, van der Beek AJ, Meerding WJ, van Mechelen W. Costs, benefits and effectiveness of worksite physical activity counseling from the employer's perspective. Scand J Work Environ Health. 2004;30(1):36-46.

63. Proper KI, van der Beek AJ, Hildebrandt VH, Twisk JW, van Mechelen W. Worksite health promotion using individual counselling and the effectiveness on sick leave; results of a randomised controlled trial. Occup Environ Med. 2004;61(3):275-279.

64. Rebergen DS, Bruinvels DJ, van der Beek AJ, van Mechelen W. Design of a randomized controlled trial on the effects of counseling of mental health problems by occupational physicians on return to work: the CO-OP-study. BMC Public Health. 2007;7:183.

65. Rebergen DS, Bruinvels DJ, Bezemer PD, van der Beek AJ, van Mechelen W. Guideline-based care of common mental disorders by occupational physicians (CO-OP study): a randomized controlled trial. J Occup Environ Med. 2009;51(3):305-312.

66. Taimela S, Malmivaara A, Justen S, et al. The effectiveness of two occupational health intervention programmes in reducing sickness absence among employees at risk. Two randomised controlled trials. Occup Environ Med. 2008;65(4):236-241.

67. Taimela S, Justen S, Aronen P, et al. An occupational health intervention programme for workers at high risk for sickness absence. Cost effectiveness analysis based on a randomised controlled trial. Occup Environ Med. 2008;65(4):242-248.

68. von Vultee PJ, Axelsson R, Arnetz B. Individual and organizational well-being of female physicians - an assessment of three different management programs. Med Gen Med. 2004;6(1):4.

69. von Vultee PJ, Arnetz B. The impact of management programs on physicians' work environment and health. A prospective, controlled study comparing different interventions. J Health Organ Manag. 2004;18(1):25-37.

70. Willert MV, Thulstrup AM, Bonde JP. Effects of a stress management intervention on absenteeism and return to work - results from a randomized wait-list controlled trial. Scand J Work Environ Health. 2011;37(3):186-195.

71. Willert M, Thulstrup A, Hertz J, Bonde J. Changes in stress and coping from a randomized three-month stress management stress management intervention. Scand J Environ Health. 2009;35(2):145-152.

72. Dierendonck D, Schaufeli WB, Buunk BP. The evaluation of an individual burnout intervention program: the role of inequity and social support. J Appl Psychol. 1998;83(3):392-407.

73. Ginsberg G, Marks I, Waters H. Cost-benefit analysis of a controlled trial of nurse therapy for neuroses in primary care. Psychol Med. 1984;14(3):683-690. 
74. Hollinghurst S, Peters TJ, Kaur S, Wiles N, Lewis G, Kessler D. Cost-effectiveness of therapist-delivered online cognitive-behavioural therapy for depression: randomised controlled trial. Br J Psychiatry. 2010;197(4):297-304.

75. Huibers MJ, Beurskens AJ, Van Schayck CP, et al. Efficacy of cognitivebehavioural therapy by general practitioners for unexplained fatigue among employees: Randomised controlled trial. Br J Psychiatry. 2004;184:240-246.

76. Kendrick T, Simons L, Mynors-Wallis L, et al. A trial of problemsolving by community mental health nurses for anxiety, depression and life difficulties among general practice patients. The CPN-GP study. Health Technol Assess. 2005;9(37):1-104, iii.

77. Kendrick T, Simons L, Mynors-Wallis L, et al. Cost-effectiveness of referral for generic care or problem-solving treatment from community mental health nurses, compared with usual general practitioner care for common mental disorders: Randomised controlled trial. Br J Psychiatry. 2006;189:50-59

78. Kessler D, Lewis G, Kaur S, et al. Therapist-delivered Internet psychotherapy for depression in primary care: a randomised controlled trial. Lancet. 2009;374(9690):628-634.

79. Lexis MA, Jansen NW, Huibers MJ, et al. Prevention of long-term sickness absence and major depression in high-risk employees: a randomised controlled trial. Occup Environ Med. 2011;68(6):400-407.

80. Nystuen P, Hagen KB. Solution-focused intervention for sick listed employees with psychological problems or muscle skeletal pain: a randomised controlled trial [ISRCTN39140363]. BMC Public Health. 2006;6:69

81. Schilte AF, Portegijs PJ, Blankenstein AH, et al. Randomised controlled trial of disclosure of emotionally important events in somatisation in primary care. Br Med J. 2001;323(7304):86.

82. Schoenbaum M, Unutzer J, Sherbourne C, et al. Cost-effectiveness of practice-initiated quality improvement for depression: results of a randomized controlled trial. JAMA. 2001;286(11):1325-1330.

83. Schoenbaum M, Unutzer J, McCaffrey D, Duan N, Sherbourne C, Wells KB. The effects of primary care depression treatment on patients' clinical status and employment. Health Serv Res. 2002; 37(5):1145-1158.

84. Wells KB, Sherbourne C, Schoenbaum M, et al. Impact of disseminating quality improvement programs for depression in managed primary care: a randomized controlled trial. JAMA. 2000;283(2):212-220.

85. Lo Sasso AT, Rost K, Beck A. Modeling the impact of enhanced depression treatment on workplace functioning and costs: a cost-benefit approach. Med Care. 2006;44(4):352-358.

86. Rost K, Smith JL, Dickinson M. The effect of improving primary care depression management on employee absenteeism and productivity. A randomized trial. Med Care. 2004;42(12):1202-1210.

87. Rutz W, Walinder J, Eberhard G, et al. An educational program on depressive disorders for general practitioners on Gotland: background and evaluation. Acta Psychiatr Scand. 1989;79(1):19-26.

88. Rutz W, von Knorring L, Walinder J. Long-term effects of an educational program for general practitioners given by the Swedish Committee for the Prevention and Treatment of Depression. Acta Psychiatr Scand. 1992;85(1):83-88.

89. van der Feltz-Cornelis CM, Hoedeman R, de Jong FJ, et al. Faster return to work after psychiatric consultation for sicklisted employees with common mental disorders compared to care as usual. A randomized clinical trial. Neuropsychiatr Dis Treat. 2010;6:375-385.

90. Yelin E, Mathias SD, Buesching DP, Rowland C, Calucin RQ, Fifer S. The impact on employment of an intervention to increase recognition of previously untreated anxiety among primary care physicians. Soc Sci Med. 1996;42(7):1069-1075.

91. Katon W, Von KM, Lin E, et al. Collaborative management to achieve treatment guidelines. Impact on depression in primary care. JAMA. 1995;273(13):1026-1031.

92. Katon W, Robinson P, Von Korff M, et al. A multifaceted intervention to improve treatment of depression in primary care. Arch Gen Psychiatry. 1996;53(10):924-932.
93. Simon GE, Katon W, Rutter C, et al. Impact of improved depression treatment in primary care on daily functioning and disability. Psychol Med. 1998;28(3):693-701.

94. Bisoffi G, Mazzi MA, Dunn G. Evaluating screening questionnaires using receiver operating characteristic (ROC) curves from two-phase (double) samples. Int J Methods Psychiatr Res. 2000;9(3):121-133.

95. Young BJ, Beidel DC, Turner SM, Ammerman RT, McGraw K, Coaston SC.Pretreatment attrition and childhood social phobia: parental concerns about medication. J Anxiety Disord. 2006;20(8):1133-1147.

96. Stata 10.0 Computer program. College Station, TX: Stata Corporation; 2006.

97. Beauregard N, Marchand A, Blanc ME. What do we know about the nonwork determinants of workers' mental health? A systematic review of longitudinal studies. BMC Public Health. 2011;11:439.

98. Blank L, Peters J, Pickvance S, Wilford J, Macdonald E. A systematic review of the factors which predict return to work for people suffering episodes of poor mental health. J Occup Rehabil. 2008;18(1):27-34.

99. Cornelius LR, van der Klink JJ, Groothoff JW, Brouwer S. Prognostic factors of long term disability due to mental disorders: a systematic review. J Occup Rehabil. 2011;21(2):259-274.

100. Andrews G, Sanderson K, Beard J. Burden of disease. Methods of calculating disability from mental disorder. Br J Psychiatry. 1998;173:123-131

101. Bair MJ, Robinson RL, Katon W, Kroenke K. Depression and pain comorbidity: a literature review. Arch Intern Med. 2003;163(20): 2433-2445

102. Bayliss EA, Bayliss MS, Ware JE Jr, Steiner JF. Predicting declines in physical function in persons with multiple chronic medical conditions: what we can learn from the medical problem list. Health Qual Life Outcomes. 2004;2:47.

103. Berardi D, Menchetti M, De Ronchi D, Rucci P, Leggieri G, Ferrari G. Late-life depression in primary care: a nationwide Italian epidemiological survey. J Am Geriatr Soc. 2002;50(1):77-83.

104. Buist-Bouwman MA, de Graaf R, Vollebergh WA, Ormel J. Comorbidity of physical and mental disorders and the effect on workloss days. Acta Psychiatr Scand. 2005;111(6):436-443.

105. Dersh J, Gatchel RJ, Polatin P, Mayer T. Prevalence of psychiatric disorders in patients with chronic work-related musculoskeletal pain disability. J Occup Environ Med. 2002;44(5):459-468.

106. Harter M, Reuter K, Weisser B, Schretzmann B, Aschenbrenner A, Bengel J. A descriptive study of psychiatric disorders and psychosocial burden in rehabilitation patients with musculoskeletal diseases. Arch Phys Med Rehabil. 2002;83(4):461-468

107. Kroenke K, Spitzer RL, Williams JB, Monahan PO, Lowe B. Anxiety disorders in primary care: prevalence, impairment, comorbidity, and detection. Ann Intern Med. 2007;146(5):317-325.

108. Saarni SI, Suvisaari J, Sintonen H, et al. Impact of psychiatric disorders on health-related quality of life: general population survey. $\mathrm{BrJ}$ Psychiatry. 2007; 190:326-332.

109. Sartorius N, Ustun TB, LecrubierY, Wittchen HU. Depression comorbid with anxiety: results from the WHO study on psychological disorders in primary health care. Br J Psychiatry Suppl. 1996;30:38-43.

110. Sherbourne CD, Wells KB, Meredith LS, Jackson CA, Camp P. Comorbid anxiety disorder and the functioning and well-being of chronically ill patients of general medical providers. Arch Gen Psychiatry. 1996;53(10):889-895.

111. Simon NM, Fischmann D. The implications of medical and psychiatric comorbidity with panic disorder. J Clin Psychiatry. 2005;66 Suppl 4 $8-15$.

112. Stein MB, Cox BJ, Afifi TO, Belik SL, Sareen J. Does co-morbid depressive illness magnify the impact of chronic physical illness? A population-based perspective. Psychol Med. 2006;36(5):587-596.

113. Wagner HR, Burns BJ, Broadhead WE, Yarnall KS, Sigmon A, Gaynes BN. Minor depression in family practice: functional morbidity, co-morbidity, service utilization and outcomes. Psychol Med. 2000;30(6):1377-1390. 
114. Whitaker SC. The management of sickness absence. Occup Environ Med. 2001;58(6):420-424.

115. Franche RL, Krause N. Readiness for return to work following injury or illness: conceptualizing the interpersonal impact of health care, workplace, and insurance factors. J Occup Rehabil. 2002;12(4):233-256.

116. Mintz J, Mintz LI, Arruda MJ, Hwang SS. Treatments of depression and the functional capacity to work. Arch Gen Psychiatry. 1992;49(10):761-768.

117. Saunders T, Driskell JE, Johnston JH, Salas E. The effect of stress inoculation training on anxiety and performance. J Occup Health Psychol. 1996;1(2):170-186.
118. Martin A, Sanderson K, Cocker F. Meta-analysis of the effects of health promotion intervention in the workplace on depression and anxiety symptoms. Scand J Work Environ Health. 2009;35(1):7-18.

119. Aust B, Helverskov T, Nielsen MB, et al. The Danish national returnto-work program - aims, content, and design of the process and effect evaluation. Scand J Work Environ Health. January 13, 2012. [Epub ahead of print.]

120. Hensing G, Alexanderson K, Allebeck P, Bjurulf P. How to measure sickness absence? Literature review and suggestion of five basic measures. Scand J Soc Med. 1998;26(2):133-144.

\section{Publish your work in this journal}

The Open Access Journal of Clinical Trials is an international, peerreviewed, open access journal publishing original research, reports, editorials, reviews and commentaries on all aspects of clinical trial design, management, legal, ethical and regulatory issues, case record form design, data collection, quality assurance and data auditing methodologies. The manuscript management system is completely online and includes a very quick and fair peer-review system, which is all easy to use. Visit http://www.dovepress.com/testimonials.php to read real quotes from published authors.

Submit your manuscript here: http://www.dovepress.com/open-access-journal-of-clinical-trials-journal 